3

7

\title{
Comparison of stresses in 3D vs 2D geomechanical modelling of salt structures in the Tarfaya basin, West African Coast
}

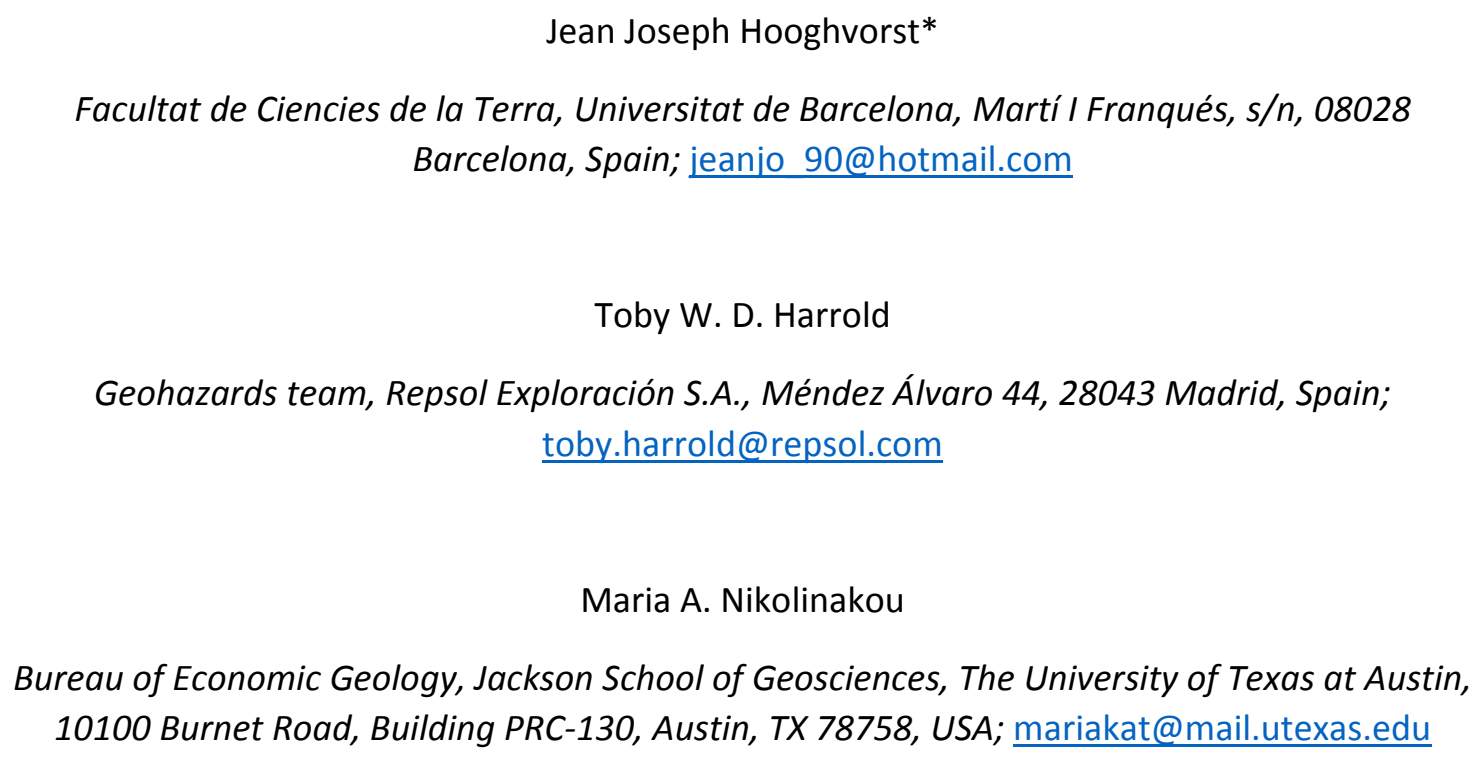


24 We predict stresses and strains in the Tarfaya salt basin on the West African Coast using a 3D static geomechanical model and compare the results against a simplified 2D plane-strain model. Both models are based on present-day basin geometries, are drained and use a poro-elastic description for the sediments and visco-plastic description for salt. We focus on a salt diapir, where an exploratory well has been drilled crossing a major fault. The 3D model shows a significant horizontal stress reduction in sediments at the top of the diapir, validated with measured data later obtained from the well. The 2D model predicts comparable stress reduction in sediments at the crest of the diapir. However, it shows a broader area affected by the stress reduction, overestimating its magnitude by as much as $1.5 \mathrm{MPa}$. Both models predict a similar pattern of differential displacement in sediments along both sides of the major fault, above the diapir. These displacements are the main cause of horizontal stress reduction detected at the crest of the diapir. Sensitivity analysis in both models show that the elastic parameters of the sediments have minimal effect on the stress-strain behavior. In addition, the 2D sensitivity analysis concludes that the main factors controlling stress and strain changes are the geometry of the salt and the difference in rock properties between encasing sediments and salt. Overall, our study demonstrates that carefully built 2D models at the exploration stage can provide stress information and useful insights comparable to those from more complex 3D geometries.

41 Keywords: Static geomechanical model, 3D vs 2D model comparison, salt diapir, minimum 42 horizontal stress reduction, sensitivity analysis, Tarfaya basin 
A great number of hydrocarbon reservoirs in basins around the world are located near or below salt structures (Meyer et al. 2005; Warren 2006; Beltrao et al. 2009; Yu et al. 2014). This fact has led to a large number of drilling operations close to salt diapirs. The viscous rheology of the salt makes it unable to sustain deviatoric stresses, therefore salt flows and changes its shape until it reaches an isostatic (uniform) stress state. As a result, sediments encasing salt structures may experience deformation and changes in their stress state and pore pressure distribution (Orlic \& Wassing 2013; Luo et al. 2017; Nikolinakou et al. 2018). This uncertainty of stress and pressure state has led to major problems during drilling operations in salt-related basins, including hazardous conditions and additional expense. For example, Bradley (1978) discusses borehole collapse incidents next to a salt structure in the Gulf of Mexico, Eugene Island. Seymour et al. (1993) reports $26.3 \%$ of non-productive drilling time for wells close to salt diapirs in the North Sea. Narrow drilling windows near salt formations in the Gulf of Mexico, leading to severe lost circulation, hole instabilities and high-pressure kicks, are also reported by Sweatman et al. (1999). Finally, Dusseault et al. (2004) exemplifies the case of a well above a Gulf of Guinea salt dome, where lower than expected minimum horizontal stresses resulted in 92 lost drilling days.

In the last twenty years, geomechanical modelling has been established as a tool to reduce poromechanical constitutive formulations to predict stress, strain and pore pressure of sediments in basins. Geomechanical models can be static (e.g., Segura et al. 2016; Heidari et al. 2018) or evolutionary (e.g., Goteti et al. 2012; Nikolinakou et al. 2018; Thigpen et al. 2019). Static models are built based on present-day geometry while evolutionary models simulate the evolution of the salt system (Nikolinakou et al. 2014). Therefore, static models are most often used to study specific prospects. Most published static studies employ 2D geomechanical models. Early examples use idealised salt geometries (e.g., Fredrich et al. 2003), which provide insights on salt-sediment interaction, but do not describe real field cases. Several 2D studies of actual salt geometries-derived from seismic surveys-have also been documented (Fredrich et al. 2007b; Segura et al. 2016; Heidari et al. 2018). Such 2D models allow preliminary results to be obtained faster than a complete 3D model. However, 2D models can only represent complex 3D salt structures with a plane-strain or axisymmetric geometry, hence they cannot incorporate stress changes and deformation associated with the three-dimensional nature of the salt system. There are a few studies that perform a full 3D geomechanical model of actual salt geometries (van der Zee et al. 2011; Adachi et al. 2012; Segura et al. 2016) overcoming the limitations of the 2D models. These models, however, have the downside of being computationally expensive and labor intensive.

At an early exploration stage, the selection of a 3D versus 2D geomechanical model becomes important. The final choice can be influenced by time and budget constraints or the required accuracy of the results. Geometric variability, complex fault networks, changes in lithologies or salt-sediment interaction can be factors that tip the balance from one approach to another.

This work presents a case study for the Tarfaya salt basin on the NW African coast (Fig. 1). A rank wildcat exploration well was drilled above a salt-cored anticline. A 3D elastic static geomechanical model was developed before the drilling of the exploration well to obtain a stress-strain understanding of the area, as well as to assess the stability of the complex 3D pattern of faults above the diapir. This 3D model concludes that a significant horizontal stress reduction is present in the sediments above the salt structure. Results of the $3 \mathrm{D}$ analysis were later validated with data from drilling of the exploration well. Sensitivity analysis on input 
material properties has also been performed, because of the lack of data for a precise material 89 description. This analysis shows almost no effect on the results.

90 A 2D model has been built from a representative transect of the full 3D geometry that includes 91 the exploration well. The results from this simpler model are consistent with the horizontal 92 stress reduction above the salt structure seen in the 3D model. The sensitivity analysis also shows low influence of the sediment elastic properties. In addition, it allows us to identify the high contrast between salt/sediment properties and the seafloor geometry as the main causes of stress and strain changes in the poro-elastic model.

96 We compare the results between the 3D and 2D models to explore whether the simplified 2D 97 case can lead to similar results as the 3D case. The comparison shows a similar reduction in magnitude of horizontal stresses in sediments located near the salt crest. However, the 2D model predicts a more extensive area of stress and strain perturbations above salt. The displacements of the roof sediments in both models have similar patterns but the $2 \mathrm{D}$ model yields higher magnitudes. These results allow us to consider the $2 \mathrm{D}$ simplification as a realistic first order simulation of the basin, in agreement with available data and results from the more complex 3D model. 
105

106

107

108

109

110

111

112

113

114

115

116

117

118

119

120

121

122

123

124

125

126

127

128

129

130

131

132

133

134

135

136

137

The study zone is located in the Tarfaya basin, between the Moroccan shore and the island of Lanzarote from the Canary Archipelago (Fig. 1). It extends approximately $3,250 \mathrm{~km}^{2}$ and comprises numerous salt bodies that are part of the structures identified along the NW African margin (Tari \& Jabour 2013).

The Tarfaya basin is characterized as a passive margin formed during the Late Triassic-Early Jurassic rifting and opening of the Central Atlantic and separation of the NW African from the North American margins. The rifting caused stretching of the basement, forming fault-controlled grabens that were filled by siliciclastic and evaporitic sediments. These evaporites were the source layer for the present-day salt structures. The uneven distribution of salt along these grabens is the principal cause for the distribution of individual salt structures at present day (Tari \& Jabour 2013).

Post-rift differential thermal subsidence and submersion of the basin towards the west favoured the formation of a carbonate shelf and triggered the salt tectonics (Tari \& Jabour 2013). During the Late Jurassic-Early Cretaceous, a relative sea-level fall caused a subaerial exposure and karstification of the carbonate platform (Wenke et al. 2011). A very significant sedimentary influx from the continental margin also takes place during the Early Cretaceous, depositing thick sand layers forming the Tan-Tan deltaic formation (Gouiza 2011).

During the Late Cretaceous, the initial compression of the Atlas began, causing a moderate sediment input (Wenke et al. 2011) and reactivating pre-existing salt structures until the Miocene. This period of time is considered by Tari and Jabour (2013) to be the main period for the formation of salt sheets and canopies seen north of the Tarfaya basin and also coincides with the volcanic emplacement of the Canary Archipelago (Carracedo \& Perez-Torrado 2013). Most of the salt structures present in the study area are still active at the present day, affecting in some cases the seafloor bathymetry (Fig. 2). The same figure shows other diapirs not reaching the seafloor due to their early welded stem, forming pinched diapirs within the basin. An exploratory well path was proposed above one of these buried salt structures and through the overlying network of faults (Fig. 3). The crest of this Triassic salt diapir is at 3,000 m BSL. The salt bulb at the top of the diapir has been interpreted on seismic to be disconnected from its autochthonous source layer due to welding of its stem. The folded geometry of the overlying Tertiary sediments indicates that salt in the bulb has risen after its original emplacement. The main objective of the exploratory well was to test the presence of hydrocarbons at four different sand-rich turbiditic deposits in the supra-salt Tertiary sediment package. A fault network located above the salt diapir cross-cuts the reservoir intervals. 
We build a 3D geomechanical model using Elfen (Rockfield 2017). The model is based on a quasistatic, drained, finite-element formulation. It uses an unstructured finite element mesh containing 3.97 million linear tetrahedral elements, with a mesh size of $400 \mathrm{~m}$. A refined mesh region $(4,000 \mathrm{~m}$ by $4,000 \mathrm{~m})$ centred in the well location is used with an element size of $50 \mathrm{~m}$. The boundary conditions applied restrict horizontal displacements at the four lateral sides of the model and restrict vertical displacements at the base. The pre-defined faults are modelled using double-sided discrete contact that allows sliding to occur along the faults as well as a stress redistribution around them. The faults use a Coulomb friction law using a cohesion of $0 \mathrm{MPa}$ and a coefficient of friction of 0.3 .

The input parameters of the model include the initial pore pressure profile, initial stress ratios (ratio between the vertical and horizontal effective stresses considering uniaxial conditions) and material properties for each horizon. We calibrated these inputs using offset well and seismic velocity analyses. The offset wells used (yellow dots in Fig. 1) are the closest deep-water analogues to the studied location. Closer wells (red dots in Fig. 1) are discarded for being located on the continental shelf, a too dissimilar environment when compared with the studied zone.

The domain included in the 3D model covers a subset of about $570 \mathrm{~km}^{2}$ of the total area of the survey shown in Fig. 2 and comprises the location of the well trajectory. The geometries for the different horizons modelled are extracted from the interpretation of the seismic survey. The base of the model is at a depth approximately $9 \mathrm{~km}$ below the seafloor, along the interpreted base of the autochthonous salt layer. Two sand layers represent the system of reservoirs above salt (Fig. 3a). The autochthonous and allochthonous salt structures are connected by $200 \mathrm{~m}$ wide salt columns. This is contrary to the seismic interpretation that shows independent bodies, but is necessary because of the software's initialisation procedures. To ensure no salt flow from the source layer, the width of the salt columns is sufficiently narrow (Fig. 3b).

The complex fault network above the salt diapir is simplified and represented by only two faults: a N-S trending fault which is the only one to have a maximum throw in excess of $400 \mathrm{~m}$, and a secondary fault that intersects the trajectory of the exploratory well (Fig. 3).

\section{INITIAL STRESS STATE}

In sediments, stress calculations are uncoupled from porous fluid flow (drained analysis). The initial pore pressure profile for each horizon is obtained from a pre-drill offset well analysis, using wells in equivalent depths from the sea surface (yellow dots in Fig. 1). The pore pressure profile for shallowest and intermediate shale layers (S1 and S2, Table 1) is hydrostatic, whereas a constant overpressure is present in sand layers and the deepest shale layer (R1, R2 and S3 layers, Table 1). There is zero pore pressure in salt.

174 Input stress ratios ( $\mathrm{K}_{\mathrm{H}}$ and $\mathrm{K}_{\mathrm{h}}$, see appendix $\mathrm{A}$ for nomenclature) are used in the model 175 initialization to obtain the initial horizontal effective stresses $\left(\sigma^{\prime}{ }_{H}, \sigma_{h}^{\prime}\right)$ as a fraction of the initial 176

$$
\begin{gathered}
\sigma_{v}^{\prime}=\sigma_{v}-u \\
K_{H}=\frac{1}{2}\left(1+K_{h}\right)
\end{gathered}
$$




$$
K_{h}=\frac{\sigma_{h}^{\prime}}{\sigma_{v}^{\prime}}, K_{H}=\frac{\sigma_{H}^{\prime}}{\sigma_{v}^{\prime}}
$$

177

where $\sigma_{v}$ is the overburden, $u$ the pore pressure, $\sigma_{H}$ the maximum horizontal stress and $\sigma_{h}$ the minimum horizontal stress.

It is assumed that the maximum horizontal stress, $\sigma_{H}$, in the studied area acts in the east-west direction due to basinward gliding of sediments on the basal salt layer. Consequently, the minimum horizontal stress, $\sigma_{h}$, is oriented in north-south direction. $\mathrm{K}_{\mathrm{h}}$ and $\mathrm{K}_{\mathrm{H}}$ (eq. 2 ) are used to obtain the initial $\sigma_{h}^{\prime}$ and $\sigma_{H}^{\prime}$ respectively (eq. 3). The initial stress ratio values can be found in Table 1 and have been obtained using the offset well data from the well analogues (Fig. 1). The salt structures have an assigned initial stress ratio value of one because salt is assumed to have a uniform stress state.

\section{MATERIAL PROPERTIES}

Porosity-depth profiles for each horizon material are calibrated at the well location based on log data. An estimate for the bulk density, $\rho_{b}$, of sediments is obtained from the measured interval velocity at the well location. The porosity is then calculated assuming values of grain and fluid densities (Table 1):

$$
n=\frac{\rho_{b}-\rho_{s}}{\rho_{w}-\rho_{s}}
$$

where $\rho_{w}$ and $\rho_{s}$ are the water and grain densities, respectively. Because horizons have different thicknesses across the field than at the well location, porosity-depth profiles for each horizon are extrapolated for the maximum depth of the given horizon.

The shales and sands are modelled as poroelastic materials. Because of very limited experimental or field data, the input elastic parameters are calibrated based on observations from regional wells (Table 1). The poroelastic behaviour is defined using an empirical expression to incorporate porosity changes (Rockfield 2017):

$$
E=E_{\text {ref }}\left[\frac{\sigma^{\prime}+A}{B}\right]^{r} n^{c}
$$

where $E$ is the elastic modulus, $E_{\text {ref }}$ a reference elastic modulus, $n$ the porosity and $A, B, r$ and $c$ are material constants used to define the shape of the elastic modulus profile. Input values can be found in appendix B, Table B1.

Note that the two reservoirs (R1 and R2, Fig. 3a) and the shale layer between them have a constant elastic modulus, $E$ that is equal to $E_{\text {ref. }}$ The shallowest and deepest shale horizons have an elastic modulus that varies with depth. This allows us to account for depth variations of material properties within these thicker horizons. The range of values of the elastic modulus, $E$, for each horizon is shown in Table 1.

The salt bodies are modelled using a steady state creep model. This is a reduced form of the Munson-Dawson formulation (the two steady-state terms are included and the transient term is omitted, considered negligible over geological time scales) (Munson \& Dawson 1979). This constitutive model considers the salt viscosity as a function of both effective stress and 
210 temperature. In the absence of field-specific data, input parameters for the salt (appendix B, 211 Table B2) are calibrated based on Avery Island salt (Munson 1997; Fredrich et al. 2007a), 212 considered to represent average salt behaviour.

213 A temperature gradient of $3.61{ }^{\circ} \mathrm{C}$ per $100 \mathrm{~m}$ is used in the model, based on an integrated 2D 214 and 3D petroleum system model for thermal maturity evaluation. The model was calibrated to 215 the offset wells, taking into consideration the variation in sedimentation, salt presence and 216 crustal structure. The gradient value used is in line with published results from the area (Rimi 217 2001; Zarhloule et al. 2010). 2D MODEL SET-UP

219 The 2D model is plane strain. The geometry is defined by taking a cross section through the 3D 220 model oriented SE to NW that passes through the exploratory well (Fig. 4). This section is not 221 oriented parallel to the maximum horizontal stress in the 3D model. The orientation of the 222 section was chosen to capture several key elements of the 3D model, such as the faults crossing 223 the well trajectory, the diapir located below the well and the anticline in the sediments overlying the salt body. In addition, other diapirs present in the 3D model are included to incorporate possible interactions between the different salt bodies. The difference between values of $\mathrm{K}_{\mathrm{H}}$ and $\mathrm{K}_{\mathrm{h}}$ shown in Table 1 are small, averaging 0.11 . Hence, choosing an orientation of $2 \mathrm{D}$ section that is not parallel to the original $\mathrm{K}_{\mathrm{H}}$ direction in the 3D model has low impact on the stress results. The boundary conditions applied restrict horizontal displacements at both sides of the model and restrict both horizontal and vertical displacements at the base.

230 The initial pore pressure profiles, stress ratio and material properties for each layer used in the $2312 \mathrm{D}$ model are the same as in the 3D model to allow a more consistent comparison between the model results. 


\section{D MODELLING}

MODEL RESULTS

The viscous rheology of the salt makes it unable to sustain deviatoric stresses, therefore salt flows and changes its shape until it reaches an isostatic (uniform) stress state. In the 3D model, salt stresses relax within 50,000 years. This salt movement loads the encasing sediments and changes their stress state. Hence, the stresses and strains at the end of the simulation represent the current day geomechanical conditions for the studied area before any drilling activity or hydrocarbon extraction.

\section{Stresses}

The minimum stress ratio (Fig. 5) is obtained from the calculated values of horizontal and vertical effective stress (eq. 3). This ratio illustrates locations in the salt system where the stresses have changed with respect to the initial stress state. Because the analysis is static (no deposition) and drained, the overburden profile and the pore pressure do not change during the simulation. As a result, the vertical effective stress (eq. 1) does not change either. Hence, a minimum stress ratio higher than its initial value implies an increase of $\sigma_{h}^{\prime}$. On the other hand, a minimum stress ratio lower than its initial value reflects a decrease of $\sigma_{h}^{\prime}$.

We identify notable stress changes in areas located near the salt structures and around the faults. Along the section A-A' and near the well location (Fig. 5b) we observe an increase of $\mathrm{K}_{\text {min }}$ near the salt source layer and a decrease above the salt diapir, both at seafloor (around the shallowest part of the fault) and near the crest of the salt body. Stress reduction above the salt is greater on the footwall side of the fault, where the well is located, reaching values below 0.55 .

We find that the maximum principal stress remains vertical and the minimum principal stress horizontal with the exception of a few small areas near salt, where the maximum stress rotation (on a vertical plane) is less than 10 degrees. In contrast, we find a notable rotation of principal stresses on the horizontal plane (Fig. 6), especially near salt diapirs (blue and red colour contours in Fig. 6). This rotation of horizontal principal stresses from their initial orientation (east-west for the maximum principal stress; azimuth $90^{\circ}$, Fig. 6) indicates loading from salt. For example, the sediments between the two diapirs located at the NW model edge experience compression from both diapirs, rotating the azimuth of the maximum horizontal stress counter-clockwise from $90^{\circ}$ to less than $60^{\circ}$. The horizontal principal stresses also rotate around the major fault.

\section{Displacements}

We focus on the direction of predicted displacements, because the assumption of elastic behaviour for the sediments underestimates their magnitude. Displacement direction can provide insights on possible patterns of salt relaxation and the interaction between diapirs and their neighbouring sediments.

The horizontal east-west displacements mainly develop towards the west throughout the model domain (blue contours in Figs. 7a and 7b) and are greater for the sediments located above the eastern diapir and around the major fault. Displacements are greater in the footwall of the fault, compared to the hanging wall (darker blue contours at footwall side in Fig. 7b). This difference in displacement magnitudes causes extension in the sediments above the diapir that explains the predicted reduction of stresses (Fig. 5b). Horizontal displacements are negligible along a north-south section through the well. 
Vertical displacements are localized around the major fault above the eastern diapir, indicating a downward movement of the hanging wall (blue contours in Figs. 7c and 7d).

\section{SENSITIVITY ANALYSIS}

All input conditions may affect the final static solution. The input with the highest uncertainty in the 3D geomechanical model is the elastic properties for the sediments, due to the lack of field data. In order to understand the influence of the elastic constants on the geomechanical results, we perform a sensitivity analysis (Table 2) focusing on the Elastic modulus and Poisson's Ratio of the shale formations (non-reservoir sediments). Variation of the elastic properties of the sand layers in the model was omitted. Sand layers represent a very small fraction of the sediment column and have little or no influence on the basin stress field.

\section{Comparison across model volume using model subtraction}

We illustrate the effect of parameter variation in sensitivity analyses by subtracting a given result of a sensitivity analysis from the basecase model:

$$
\text { Comparison ratio }(S)=\frac{\text { Basecase model }- \text { Senstivity model }}{\text { Basecase model }}
$$

This is possible because the numerical mesh is the same in all models, allowing node by node comparison. Values of $S$ close to zero imply a small change in the results caused by changing the studied elastic parameter. In contrast, larger values of S indicate that the difference between the compared models is greater and thus, the impact of the studied elastic parameter is more significant.

A statistical summary of the sensitivity analysis comparison results is shown in Table 3 . In addition to the values of average, median, and standard deviation, the percentage of omitted nodes for the analysis is also presented for each variable studied. These have locally spurious values which would skew the comparison between models if they were included. They constitute a very small fraction of the nodes in the model (0 to $2 \%$; Table 3 ).

The median values for the principal stresses are very close to zero in each of the comparison cases with small standard deviations, meaning that the changes imposed on the elastic parameters had little impact on the basecase results.

The median and standard deviation values for the displacement results are greater than the ones for the principal stresses. However, they still represent a small change in the basecase results. It should be noted that because of the elastic assumption for sediment behavior, displacements in all these models are very low, less than $2 \mathrm{~m}$ in any of the 3 principal directions (Fig. 7).

\section{Comparison of sensitivity results along the well trajectory}

We also compare results of the sensitivity analysis (Table 2) along the well trajectory (Fig. 8), for the first $1,000 \mathrm{~m}$ below seafloor. We find that variations in either Elastic Modulus or Poisson's Ratio have little impact on the horizontal stress, with the greatest difference being lower than an equivalent mudweight of 0.15 ppg (pounds per gallon). 
Similar to the 3D case, the 2D geomechanical results represent the current day stress and strain conditions.

Displacements calculated with the 2D model illustrate how the salt flows and how this affects the sediment strain and stress state. In particular, the eastern diapir exhibits a downwards flux at its eastern side and a westwards movement at its western part, causing the diapir to collapse and spread laterally (red arrows in Fig. 9). The same differential movement is also seen in the sediments encasing the diapir (green arrows in Fig. 9). As a result, the footwall of the fault undergoes a greater westwards displacement than the hanging wall, which moves mainly downward. In other words, the pattern of salt relaxation can explain the differential displacements above salt observed both in 2D (Fig. 9) and 3D (Fig. 7b) models, and is interpreted to be responsible for the decrease in horizontal stress above the diapir's crest.

The horizontal strain profile confirms the extensional zone located above the eastern diapir due to the differential sediment displacements (red contours in Fig. 10). The maximum extension occurs immediately above the crest of the salt structure. Localized shortening horizontal strains develop near the flanks of the western diapir (blue contours in Fig. 10), resulting from the lateral expansion of the salt diapir in the shallow section.

Extensional strains (Fig. 10) correspond to a horizontal-to-vertical effective stress ratio lower than its initial value of 0.8 (blue contours in Fig. 11a). In contrast, shortening strains (Fig. 10) correspond to a stress ratio higher than its initial value (red contours in Fig. 11a). The stress ratio reduction in the sediments above the eastern diapir is maximum immediately above the crest of the salt structure and where the faults reach the seafloor.

A stress profile has been extracted along the crest of the salt structure (W profile in Fig. 11a) in order to compare geomechanical stress results with uniaxial stresses along a sediment column having the same burial depth (Fig. 11b). The uniaxial vertical effective stress (dashed lines in Fig. $11 b$ ) is calculated from the overburden weight of sediments and assigned pore pressure (eq. 1). Then, the horizontal effective stress is calculated using the initial stress ratio (eq. 3). We find that the geomechanical horizontal stress (solid green line in Fig. 11b) is consistently lower than its uniaxial value and decreases notably within $1 \mathrm{~km}$ from the crest of the salt structure, with a maximum difference of around 4.5 $\mathrm{MPa}$ at the salt-sediment interface. This reduction is consistent with the stress ratio reduction near the crest of the eastern diapir (Fig. 11a) and illustrates the effect of the extensional strains on sediment stress. The vertical stress predicted by the geomechanical model (solid blue line in Fig. 11b) remains close to the uniaxial value, with a slight increase just above the salt. 
347 Similar to the 3D model, a 2D model sensitivity analysis has been performed to assess the 348 influence of the different model assumptions over the final results. In addition to changes in 349 elastic parameters, other structural framework changes have been tested using 2D models 350 (Table 4) that were too complex to test in 3D, due to limitations of computational power and 351 time availability. Performing these additional changes and studying their impact on the final 352 results provides insights on the main mechanisms that change stress and strain in the salt basin.

353 Changes in the shale elastic parameters resulted in less than $0.01 \%$ variation in the magnitude 354 of stress relative to the basecase 2D model. The magnitude of stress changes is ten times greater 355 than that seen in the 3D sensitivity analysis models; however, both changes are insignificant. 356 Hence, changing the elastic parameters within reasonable values does not affect the overall 357 results.

358 Substitution of salt with shale in all three diapirs allows us to explicitly see the contribution of 359 salt creep in the stress and strain changes across the model. Stresses along vertical profile W 360 (Fig. 11a) remain uniaxial when the salt volumes are assigned the shale rheology (Fig. 11b). This 361 confirms that the decrease in horizontal stress (solid green line in Fig. 11b) and stress ratio (blue 362 contours above eastern diapir in Fig. 11a) result from the deformation of the salt (red arrows in 363 Fig. 9).

364 Defining a flat seafloor mainly changes the pattern of sediment displacements across the model.

365 Sediment displacements are primarily westward in the basecase model, but they become 366 vertical when the seafloor slope is removed.

367 A model without the central and western diapirs shows less horizontal stress reduction above 368 the eastern diapir when compared to the basecase model. The displacements above the eastern 369 diapir have the same distribution as the basecase (Fig. 9) but with a lower magnitude in its 370 western side. In other words, the presence of the other diapirs translates to higher westwards 371 displacements across the model.

372 Finally, increasing the width of the salt columns that connect the salt source layer with the 373 diapirs has a low influence in the final stress field. 
The stress results from both the 3D and 2D models show a horizontal stress reduction located at the crest of the eastern diapir. In addition, both models agree on the two different displacement patterns seen above the eastern diapir (Figs. 7 and 9):

- A significant downwards component of displacement in the hanging wall (eastern side of the main fault) caused by the salt withdrawal below.

- A westwards displacement in both the salt and the footwall sediments of the main fault.

This differential movement causes extensional horizontal strain above the diapir (Fig. 10). This extension is directly linked to the horizontal stress reduction and, hence, the stress ratio reduction seen both in the $3 \mathrm{D}$ model and the $2 \mathrm{D}$ model (Figs. 5 and 11). Furthermore, it is manifested by the faults located above the diapir.

When the salt lithology in the 2D model is replaced by shale, the lateral strain and the stress reduction are not present (Fig. 11b). From this we conclude that the difference in rock properties between the salt and the encasing sediments is one of the main drivers of the reduction in horizontal stress above the salt body.

In addition, the two different displacement patterns above the eastern diapir causing the extension of the sediments at the crest are not present when the seafloor is horizontal. This demonstrates that the seafloor geometry also drives the stress reduction above salt.

During the drilling operations of the exploratory well, the stress reduction was validated with data from formation integrity tests (FIT) and leak-off tests (LOT) measurements (Fig. 12). Detection of drilling induced tensile fractures (DITF) at a depth of 2,600 $\mathrm{m}$ allowed an additional estimation of the minimum horizontal stress (green dots in Fig. 12), which agrees with the LOT data and confirms the stress reduction.

Horizontal stress reduction and lateral extensional strains in sediments above diapirs has been observed in geomechanical models using both idealized geometries (Luo et al. 2012; Nikolinakou et al. 2012) and actual salt geometries (Barnichon et al. 1999; Segura et al. 2016). Other authors report the presence of normal faults in the sediments above salt structures (Davis et al. 2000; Dusseault et al. 2004), indicating extensional regimes in these areas. Dusseault et al. (2004) also report an area of exceptionally low values of minimum horizontal stress in an anticlinal structure above a Gulf of Guinea salt dome.

\section{$2 D$ vs 3D MODELLING COMPARISON}

Comparison of results from the 3D and the 2D models allow us to identify differences in prediction and investigate whether 2D modelling-despite its simplifications-can still represent stresses in the salt basin adequately.

We have found that both $3 \mathrm{D}$ and $2 \mathrm{D}$ models predict a reduction in the stress ratio above the salt crest. However, the area of low stress ratio is broader and extends shallower in the 2D model (Fig. 11) than in the 3D model (Fig. 5). Only at the salt crest do both modelling approaches predict the same value (stress ratio of 0.6 , reduced from the initial value of 0.8 ). We also found that the direction of displacements in the sediments above the salt structure is consistent between the 3D and 2D models (Figs. 7 and 9). In both cases, the footwall has greater westward displacements than the hanging wall. At the same time, the hanging wall has a greater 
downward displacement than the footwall. Although displacements are qualitatively similar, the 2D model consistently predicts higher magnitudes than the 3D model.

Elastic theory can explain why the 2D model predicts broader areas of decreased horizontal stress and higher magnitudes of sediment displacement above salt than the 3D model. We use elastic solutions for stress distribution resulting from a load applied on a semi-infinite, elastic, isotropic and homogeneous medium (Boussinesq 1885). Specifically, we compare the vertical stress distribution with depth caused by the application of a strip load (infinite out-of-plane length) with that of a circular load (Fig. 13). Both loads result in the same applied stress q. The width of the strip load, B, is equal to the diameter of the circular one (Fig. 13). The strip and circular case represent a 2D plane-strain and a 3D axisymmetric load, respectively. Elastic theory shows that the vertical stress perturbation caused by the application of the strip load (equivalent to plane-strain model) is broader than the application of circular load (equivalent to the axisymmetric model); the circular load generates a stress perturbation that is more localised and dissipates faster with distance. For example, if we consider a value of $B=1 \mathrm{~m}$ and an applied stress $\mathrm{q}=1 \mathrm{MPa} / \mathrm{m}$, then at a distance of $6 \mathrm{~m}$ from the load application surface, the vertical stress is $0.1 \mathrm{MPa}$ for the strip load case (red dot in Fig. 13) but only $0.015 \mathrm{MPa}$ for the circular load case (blue dot in Fig. 13).

In our geomechanical models, loading is applied by the salt (in the form of imposed strain). Hence, for a simplified application, we consider the width of the salt crest to be the loading area (equivalent to $B$ in Fig. 13). The 2D model is analogous to the strip load case in Figure 13, because it is plane-strain, which corresponds to an infinitely long salt wall. Similarly, the 3D model can be compared to the circular load from Figure 13, because the salt geometry in $3 \mathrm{D}$ is relatively circular (Fig. 3). Based on Boussinesq's elastic theory, the 3D salt load should result in a smaller region of stress changes, closer to the crest (i.e., location of load application). Indeed, this is consistent with our geomechanical results (Fig. 14).

The difference between the 2D and 3D models is further illustrated by plotting the horizontal stress change (eq. 7), against the depth normalized by the depth of the salt crest, $\mathrm{H}$ (Fig. 15) for both models along vertical profile $W$ for the 2D model and $W^{\prime}$ for the 3D model (Fig. 14):

$$
\Delta \sigma_{h}^{\prime}=\sigma_{h, \text { initial }}^{\prime}-\sigma_{h \text {,model }}^{\prime}
$$

Both models predict a horizontal stress reduction of around 4.5 MPa at the crest of the salt structure. However, the 2D model predicts higher horizontal stress reduction along the vertical profile, reaching a maximum difference of $1.5 \mathrm{MPa}$ from the 3D model at $80 \%$ of the crest depth. In the 3D model, the horizontal stress change becomes zero at half the crest depth. At the same depth, the $2 \mathrm{D}$ horizontal stress reduction is $0.7 \mathrm{MPa}$. In fact, the salt influence in the 2D model extends along two thirds of the vertical profile, up to $30 \%$ of the crest depth. Note that this difference between 2D and 3D geomechanical results would be less if the simulated structure resembled more closely a salt wall.

\section{INPUT UNCERTAINTY AND LIMITATIONS}

Sensitivity analysis allowed us to quantitatively compare the effect of different model assumptions. We found that change in elastic parameters had no significant effect in both 2D and 3D models. Parameters that have a larger impact on the stress distribution in this study are: 
1) The presence of salt lithology (9\%);

2) The presence of other salt diapirs in the 2D section (7\%);

3) Seafloor slope which imposes a differential load across the width of the model (4\%);

4) The connection between the diapirs and the autochthonous salt source layer (3\%).

The percentage indicated for each scenario represents the change in stress relative to the basecase.

These are interesting fundamental observations that should be considered when designing a geomechanical model and given greater weight than the elastic properties of the sediments.

In this study, we focus on the understanding and comparison of 3D and 2D geomechanical static model approaches. This study can be improved in various ways:

- We assume these models are drained, hence the effect of salt movement on pore pressure generation is not considered. Coupling porous fluid flow with salt deformation in our models would provide a more complete prediction of stress, strain and pore pressure.

- Sediments are modelled behave as poro-elastic materials. One of the conclusions of the sensitivity analysis is the low impact of elastic properties over the results. Hence, a simpler elastic model other than eq. 5 could be used.

- Introducing plasticity and frictional strength in the sediment description will result in more realistic displacements and can help detect regions where the material is close to failure.

- One set of frictional properties were assumed for the faults. A sensitivity analysis of these frictional parameters would help better understand the interrelation between salt deformation and sediment stress reduction.

- The temperature gradient used in the 3D and 2D models has not been varied during the sensitivity analysis. This is because the variation of temperature would mainly affect the viscosity of the salt lithology, hence the time needed for the static model to converge to a solution. Temperature effects become more important in evolutionary models of salt systems.

In fact, the introduction of evolutionary geomechanical modelling can help study the complete stress-strain history through time. Our models are static and assume an initial stress distribution that changes when the salt moves. An evolutionary approach would forgo this initial assumption and would provide a complete evolution of the salt structures and how this evolution affects the basin stresses. Nonetheless, our study presents an explanation for the stress and strain changes due to the presence of salt in the Tarfaya Basin and provides considerations for deciding between a 2D and a 3D approach. 
492 We developed a 3D model of Tarfaya salt basin, on the West African coast. We focused on a salt 493 structure where an exploratory well was later drilled. We found a decrease in horizontal stress 494 near the crest of the salt and rotation of the horizontal principal stresses. Sensitivity analysis performed on the elastic parameters for the different shale horizons showed a negligible impact on the final results. In addition, we detected higher horizontal E-W displacements at the footwall of the major fault above the salt structure and higher vertical displacements at its hanging wall.

A 2D section was built from the 3D geometry to intersect the salt and exploration well. The stress results from the $2 \mathrm{D}$ model show a similar horizontal stress reduction. The $2 \mathrm{D}$ model, however, predicts a broader area of stress perturbation above the salt. Overall comparison between the $3 \mathrm{D}$ and $2 \mathrm{D}$ models show that the $2 \mathrm{D}$ model overestimates both stress changes and displacements in areas above salt. A quantitative comparison between the models along a vertical well passing through the salt crest shows that the extent of salt influence on suprasalt sediments is $20 \%$ shallower in the 2D model: sediments located at the shallower half of the vertical profile in the 3D model do not experience any stress change, whereas in the 2D model, there is still $0.7 \mathrm{MPa}$ of stress reduction (16\%) at the middle of the vertical profile. This is due to the fact that a plane-strain 2D model misrepresents the stress changes caused by a 3D loading.

The 2D model allows for a more exhaustive sensitivity analysis thanks to the considerably reduced number of elements present and computational power required. We found that the difference in rock rheology between the salt and encasing sediments is one of the main drivers of stress changes. As such, attention should be given to the definition of the salt geometry.

512 In conclusion, we found that a 2D model of the prospect is a valid alternative to the more 513 complex and time-consuming 3D modelling. The insights provided by the $2 \mathrm{D}$ model can be used 514 to obtain stress and strain information in an early exploration stage despite the overestimation 515 in their magnitude and extent. A 2D approach would be more accurate for a prospect with salt 516 walls or elongated diapirs. On the other hand, 2D models would overestimate stress and strain 517 in prospects with more circular salt bodies. In such cases, a 3D model may be considered as a 518 better approach.

\section{ACKNOWLEDGEMENTS}

520 This work is funded by Repsol Exploración S. A. We are grateful to Repsol for granting access to 521 the data for this study. We would also like to thank Rockfield for their support in the modelling using ELFEN licenses and their cluster for the 3D sensitivity analysis. We thank Dr. Kevin J. Smart,

523 Dr. Christopher Beaumont, as well as the co-editor Dr. Rajesh Goteti for their thoughtful 524 corrections. 


\section{References}

Adachi, J., Nagy, Z.R., Sayers, C.M., Smith, M. \& Becker, D.F. 2012. Drilling Adjacent to Salt Bodies: Definition of Mud Weight Window and Pore Pressure Using Numerical Models and Fast Well Planning Tool. SPE Annual Technical Conference and Exhibition, 1-11, https://doi.org/10.2118/159739-MS.

Barnichon, J.D., Havenith, H., Hoffer, B., Charlier, R., Jongmans, D. \& Duchesne, J.C. 1999. The deformation of the Egersund-Ogna anorthosite massif, south Norway: Finite-element modelling of diapirism. Tectonophysics, 303, 109-130, https://doi.org/10.1016/S00401951(98)00247-9.

Beltrao, R.L.C., Sombra, C.L., Lage, A.C.V.M., Fagundes Netto, J.R. \& Henriques, C.C.D. 2009. Challenges and New Technologies for the Development of the Pre-Salt Cluster, Santos Basin, Brazil. Houston, Texas, https://doi.org/10.4043/19880-MS.

Boussinesq, M.J. 1885. Applications Des Potentiels à l'étude de l'équilibre et Du Mouvement Des Solides Élastiques. Lille, Imprimerie L. Danel.

Bradley, W.B. 1978. Bore hole failure near salt domes. Society of Petroleum Engineers of AIME.

Carracedo, J.C. \& Perez-Torrado, F.J. 2013. Teide Volcano. Carracedo, J. C. \& Troll, V. R. (eds). Berlin, Heidelberg, Springer Berlin Heidelberg, Active Volcanoes of the World, https://doi.org/10.1007/978-3-642-25893-0.

Davis, T., Warner, M., Elders, C. \& Davison, I. 2000. Tertiary Faulting Patterns and Growth History of Central Graben Salt Diapirs.

Dusseault, M.B., Maury, V. \& Sanfilippo, F. 2004. Drilling Around Salt : Stresses, Risks, Uncertainties. American Rock Mechanics Association. Paper 04-647.

Fredrich, J.T., Coblentz, D., Fossum, A.F. \& Thorne, B.J. 2003. Stress Perturbations Adjacent to Salt Bodies in the Deepwater Gulf of Mexico. SPE Annual Technical Conference and Exhibition, 5-8, https://doi.org/10.2118/84554-MS.

Fredrich, J.T., Fossum, A.F. \& Hickman, R.J. 2007a. Mineralogy of deepwater Gulf of Mexico salt formations and implications for constitutive behavior. Journal of Petroleum Science and Engineering, 57, 354-374, https://doi.org/10.1016/j.petrol.2006.11.006.

Fredrich, J.T., Engler, B.P., Smith, J.A., Onyia, E.C. \& Tolman, D.N. 2007b. Predrill Estimation of Subsalt Fracture Gradient: Analysis of the Spa Prospect to Validate Nonlinear Finite Element Stress Analyses. SPE/IADC Drilling Conference, 8, https://doi.org/10.2118/105763-MS.

Goteti, R., Ings, S.J. \& Beaumont, C. 2012. Development of salt minibasins initiated by sedimentary topographic relief. Earth and Planetary Science Letters, 339-340, 103-116, https://doi.org/10.1016/j.epsl.2012.04.045.

Gouiza, M. 2011. Mesozoic Source-to-Sink Systems in NW Africa: Geology of Vertical Movements during the Birth and Growth of the Moroccan Rifted Margin: Ph.D Thesis. VU University Amsterdam.

Heidari, M., Nikolinakou, M.A. \& Flemings, P.B. 2018. Coupling geomechanical modeling with seismic pressure prediction. Geophysics, 83, 1-54, https://doi.org/10.1190/geo20170359.1.

Luo, G., Nikolinakou, M.A., Flemings, P.B. \& Hudec, M.R. 2012. Geomechanical modeling of stresses adjacent to salt bodies: Part 1 - Uncoupled models. AAPG Bulletin, 96, 43-64, 
Luo, G., Hudec, M.R., Flemings, P.B. \& Nikolinakou, M.A. 2017. Deformation, stress, and pore pressure in an evolving suprasalt basin. Journal of Geophysical Research: Solid Earth, 122, 5663-5690, https://doi.org/10.1002/2016JB013779.

Meyer, D., Zarra, L., Rains, D., Meltz, B. \& Hall, T. 2005. Emergence of the Lower Tertiary Wilcox trend in the deepwater Gulf of Mexico. World Oil, 226, 72-77.

Munson, D.E. 1997. Constitutive model of creep in rock salt applied to underground room closure. International journal of rock mechanics and mining sciences \& geomechanics abstracts, 34, 233-247, https://doi.org/10.1016/S0148-9062(96)00047-2.

Munson, D.E. \& Dawson, P.R. 1979. Constitutive model for the low temperature creep of salt (with application to WIPP). SAND79-1853. Sandia National Laboratories, Albuquerque, NM. 31.

Nikolinakou, M.A., Luo, G., Hudec, M.R. \& Flemings, P.B. 2012. Geomechanical modeling of stresses adjacent to salt bodies: Part 2 - Poroelastoplasticity and coupled overpressures. AAPG Bulletin, 96, 65-85, https://doi.org/10.130e/041111.10144.

Nikolinakou, M.A., Hudec, M.R. \& Flemings, P.B. 2014. Comparison of evolutionary and static modeling of stresses around a salt diapir. Marine and Petroleum Geology, 57, 537-545, https://doi.org/10.1016/j.marpetgeo.2014.07.002.

Nikolinakou, M.A., Heidari, M., Flemings, P.B. \& Hudec, M.R. 2018. Geomechanical modeling of pore pressure in evolving salt systems. Marine and Petroleum Geology, 93, 272-286, https://doi.org/10.1016/j.marpetgeo.2018.03.013.

Orlic, B. \& Wassing, B.B.T. 2013. A Study of Stress Change and Fault Slip in Producing Gas Reservoirs Overlain by Elastic and Viscoelastic Caprocks. Rock Mechanics and Rock Engineering, 46, 421-435, https://doi.org/10.1007/s00603-012-0347-6.

Rimi, A. 2001. Carte du gradient géothermique au Maroc. Bulletin de l'institut scientifique, Rabat, 23, 1-6.

Rockfield. 2017. Elfen Explicit Manual (Version 4.10). Software, R. (ed.). Swansea, UK.

Segura, J.M., Matos da Cruz, A., Stachlewski, G., Alvarellos, J., Vargas, P.E. \& Lakshmikantha, M.R. 2016. Fault stability assessment for well planning : a case study related to salt structures. American Rock Mechanics Association. Paper 16-518.

Seymour, K.P., Rae, G., Peden, J.M. \& Ormston, K. 1993. Drilling close to salt diapirs in the North Sea. Offshore Europe, 193-204, https://doi.org/10.2118/26693-MS.

Sweatman, R., Faul, R. \& Ballew, C. 1999. New Solutions for Subsalt-Well Lost Circulation and Optimized Primary Cementing. SPE Annual Technical Conference and Exhibition.

Tari, G. \& Jabour, H. 2013. Salt tectonics along the Atlantic margin of Morocco. Geological Society, London, Special Publications, 369, 337-353, https://doi.org/10.1144/SP369.23.

Thigpen, J.R., Roberts, D., Snow, J.K., Walker, C.D. \& Bere, A. 2019. Integrating kinematic restoration and forward finite element simulations to constrain the evolution of salt diapirism and overburden deformation in evaporite basins. Journal of Structural Geology, 118, 68-86, https://doi.org/10.1016/j.jsg.2018.10.003.

US Army Corps of Engineers. 1990. Engineering and Design: Settlement Analysis. Engineering Manual 1110-1-1904, CECW-EG Date 30 September 1990. 
610

611

612

613

614

615

616

617

618

619

620

621 van der Zee, W., Ozan, C., Brudy, M. \& Holland, M. 2011. 3D geomechanical modeling of complex salt structures. SIMULIA Customer Conference, 1-16.

Warren, J.K. 2006. Evaporites: Sediments, Resources and Hydrocarbons. Netherlands, Springer, https://doi.org/10.1007/3-540-32344-9.

Wenke, A., Zühlke, R., Jabour, H. \& Kluth, O. 2011. High-resolution sequence stratigraphy in basin reconnaissance: Example from the Tarfaya Basin, Morocco. First Break, 29, 85-96.

Yu, Y., Tang, L., Yang, W., Huang, T., Qiu, N. \& Li, W. 2014. Salt structures and hydrocarbon accumulations in the Tarim Basin, northwest China. AAPG Bulletin, 98, 135-159, https://doi.org/10.1306/05301311156.

Zarhloule, Y., Rimi, A., Boughriba, M., Barkaoui, A.E. \& Lahrach, A. 2010. The Geothermal Research in Morocco : History of 40 Years. In: World Geothermal Congress. 


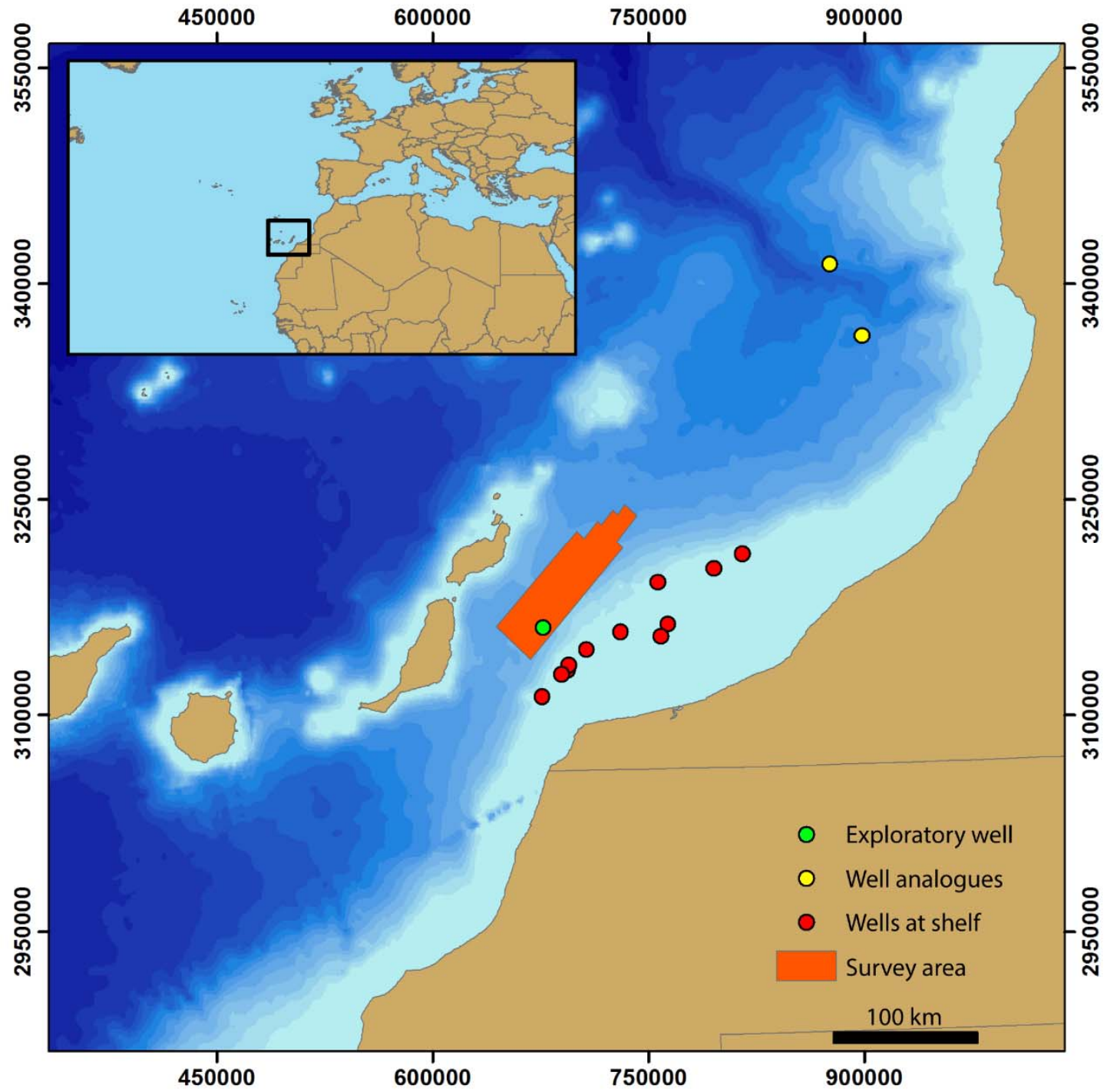

623 Fig. 1. Location map of the survey area (red polygon), located between the Canary Archipelago 624 and the southern Moroccan shore. The green dot indicates the location of the exploratory well. 


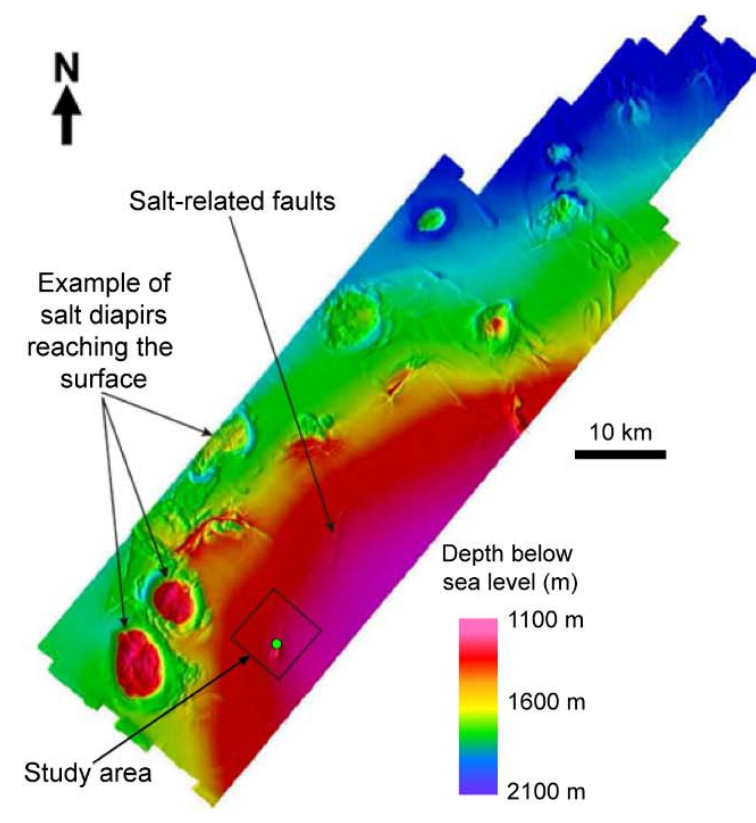

626

627

628

629

630

631

632

633

634

(a) Seabed topography source layer and buried diapirs.

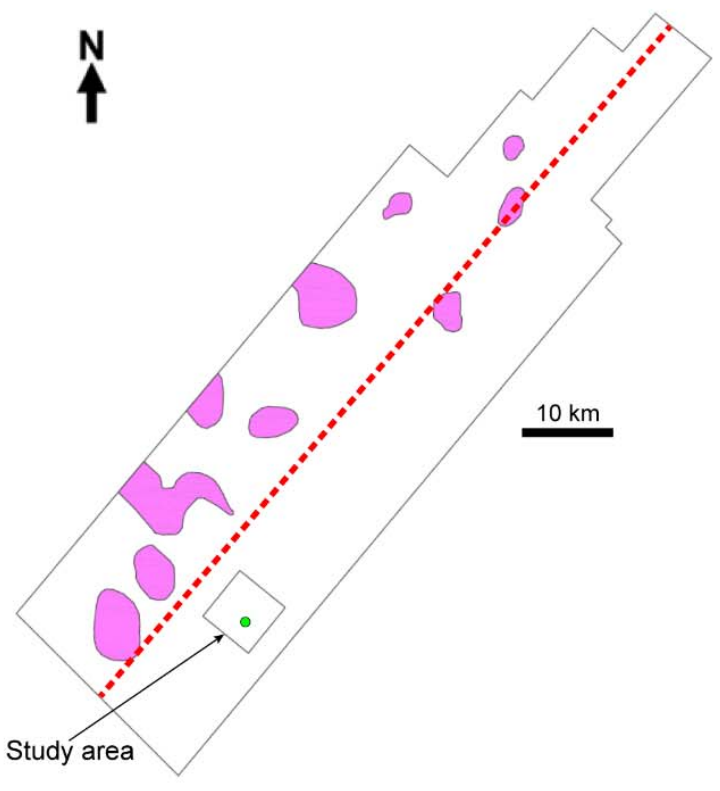

(b) Survey zone with diapirs reaching surface

general NW downward slope is perturbed by salt-related morphologies: domes with moats caused by the salt reaching the surface and seafloor troughs related to buried salt-induced faults. Rectangle indicates study area and green dot the exploration well. (b) Location of major diapirs with seabed expression (pink polygons). Red dashed line separates two different salt regions: northwest side has a thicker salt source layer, which allows diapirs to reach the seafloor, whereas southeast side has a thinner salt 


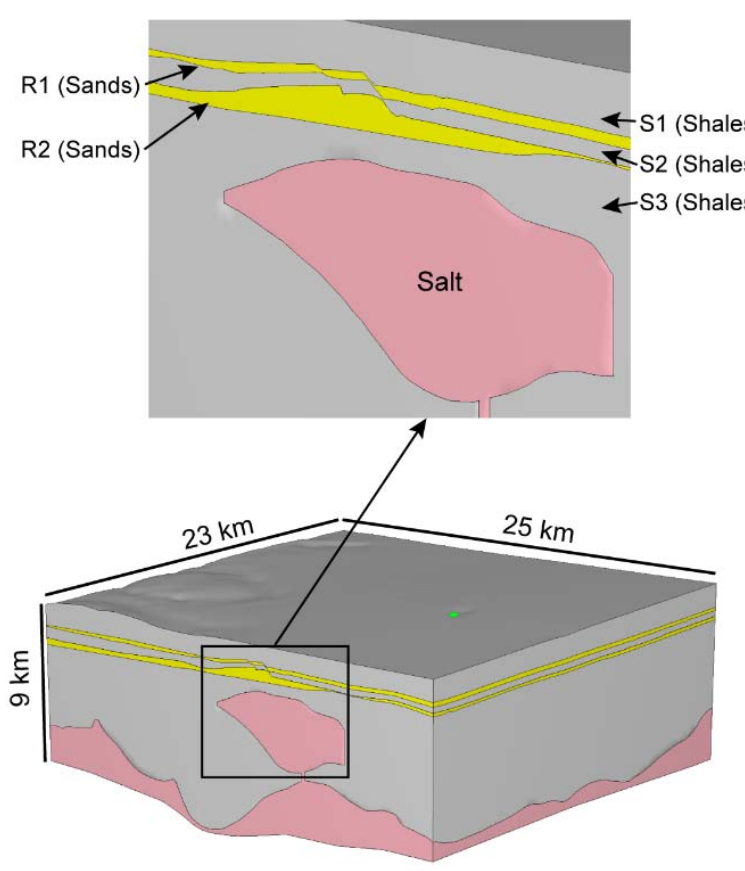

(a) Full 3D model geometry

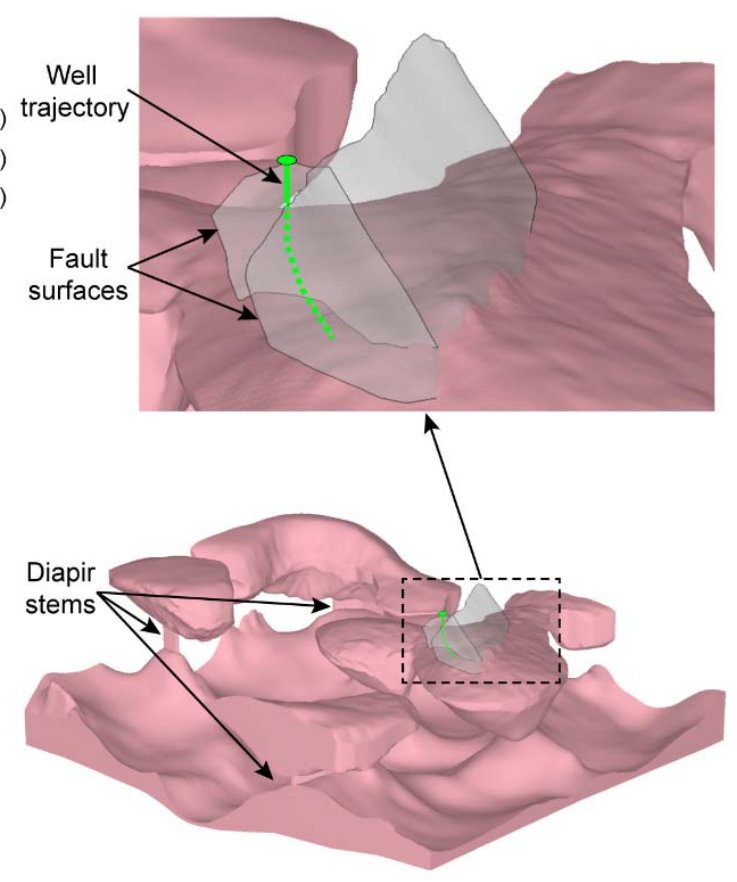

(b) Salt structure and faults within the 3D model

Fig. 3. Static 3D geomechanical model. (a) Model geometry representing stratigraphic distribution of sand, shale and salt horizons. Green dot indicates the position of well. (b) 3D salt structure, major faults and well trajectory (green line). 


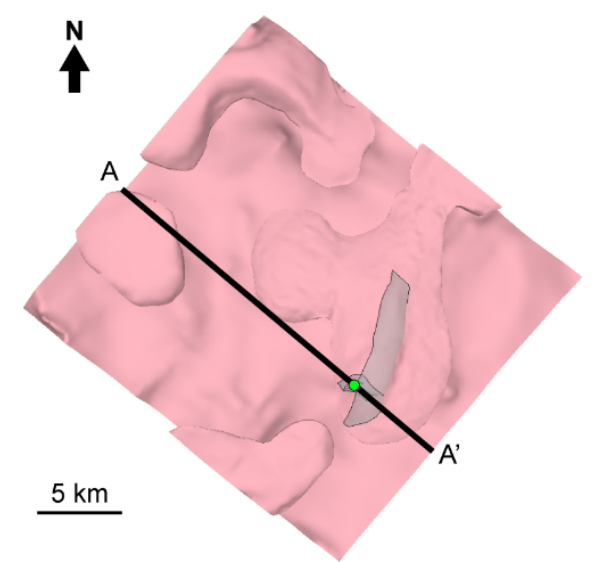

640

(a) 3D model

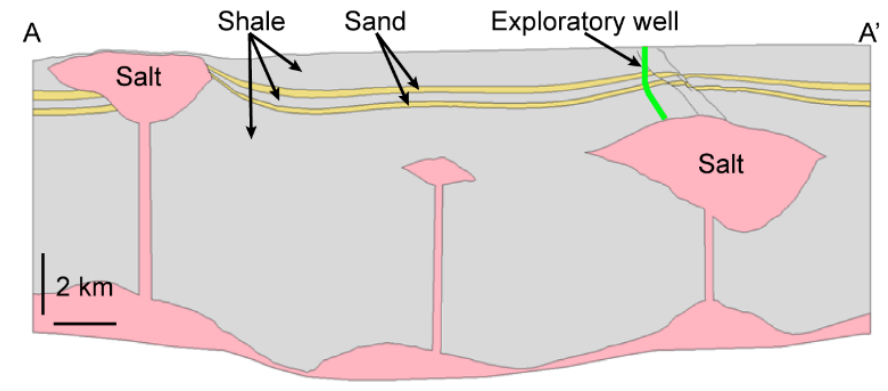

(b) 2D model

641 Fig. 4. (a) Location of cross section A-A' used for the 2D model geometry. The green dot indicates 642 the position of the exploratory well. (b) Geometry of cross section A-A' used to build the 2D 643 model. 


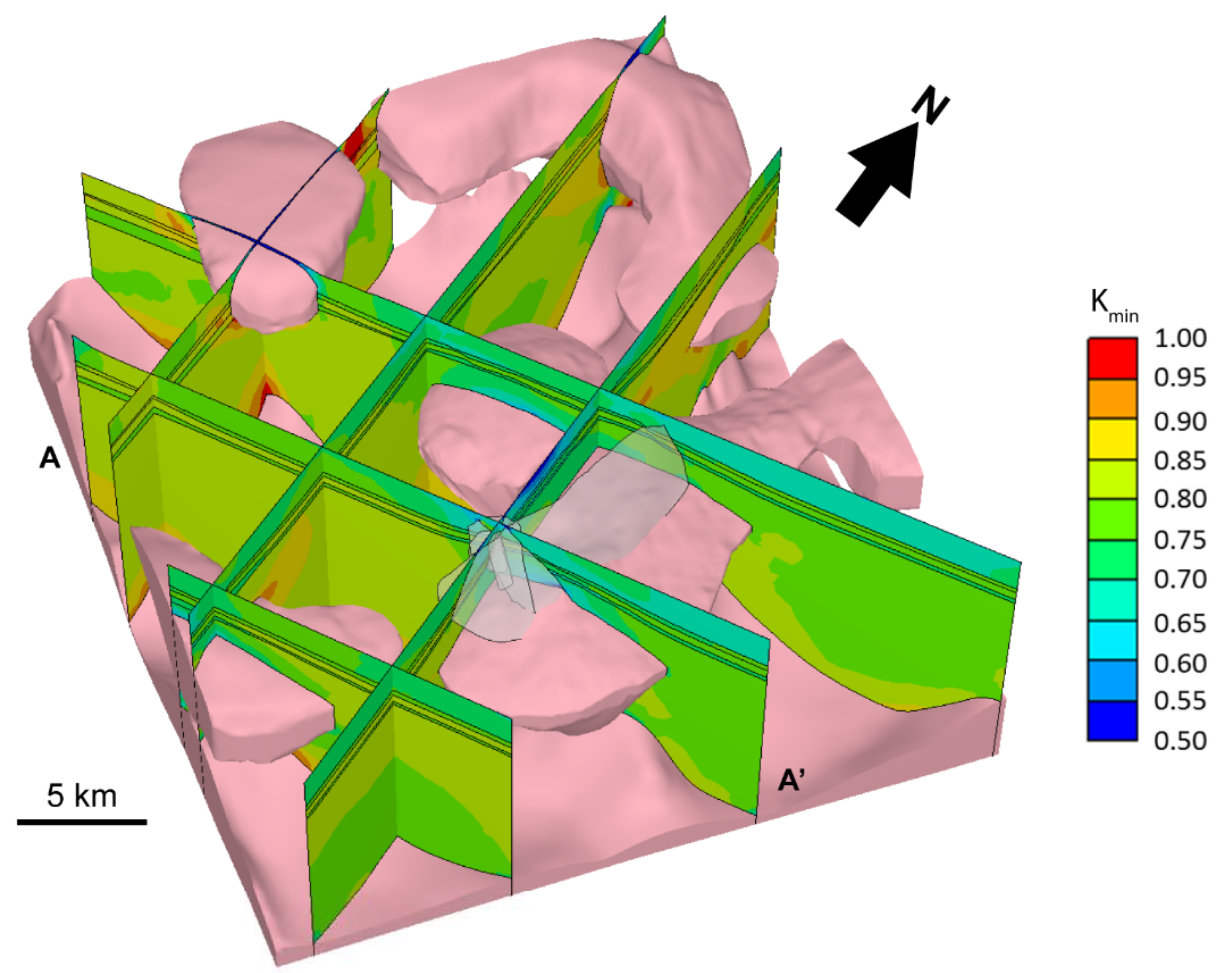

(a) $K_{\min }$ results across the 3D model

A

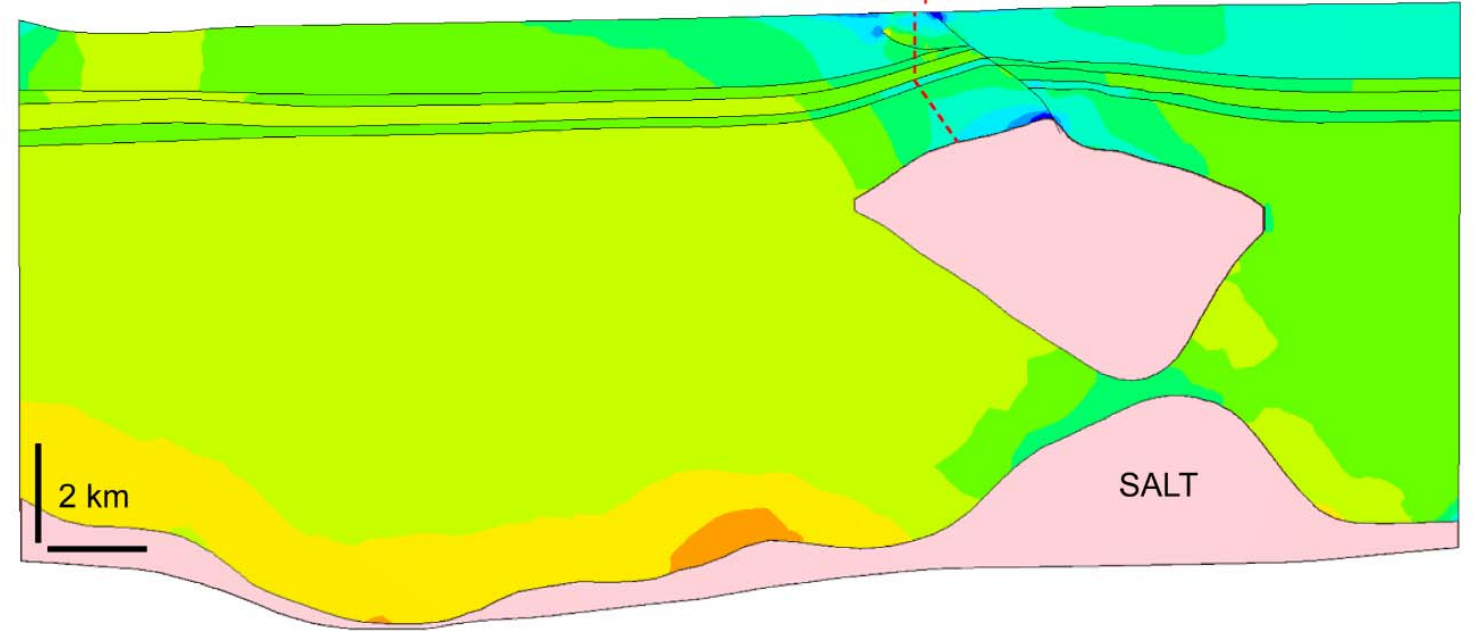

(b) $K_{\min }$ results at section A-A

Fig. 5. (a) Minimum stress ratio $\left(\mathrm{K}_{\mathrm{min}}\right)$ for different vertical sections across the model. The stress ratio is higher than its corresponding initial value for sediments below salt or near deeper salt structures. In contrast, the stress ratio is lower than its initial value at shallow depths above salt, around the faults and near the crest of the eastern salt body. (b) Minimum stress ratio $\left(K_{\min }\right)$ for section A-A' near the well location. The stress ratio is notably reduced at the bottom part of the well above salt. Initial minimum stress ratio is 0.8 (light green contour colour) for intermediate and deepest shales, and 0.75 (dark green contour colours) for the shallowest shales and two reservoirs. 


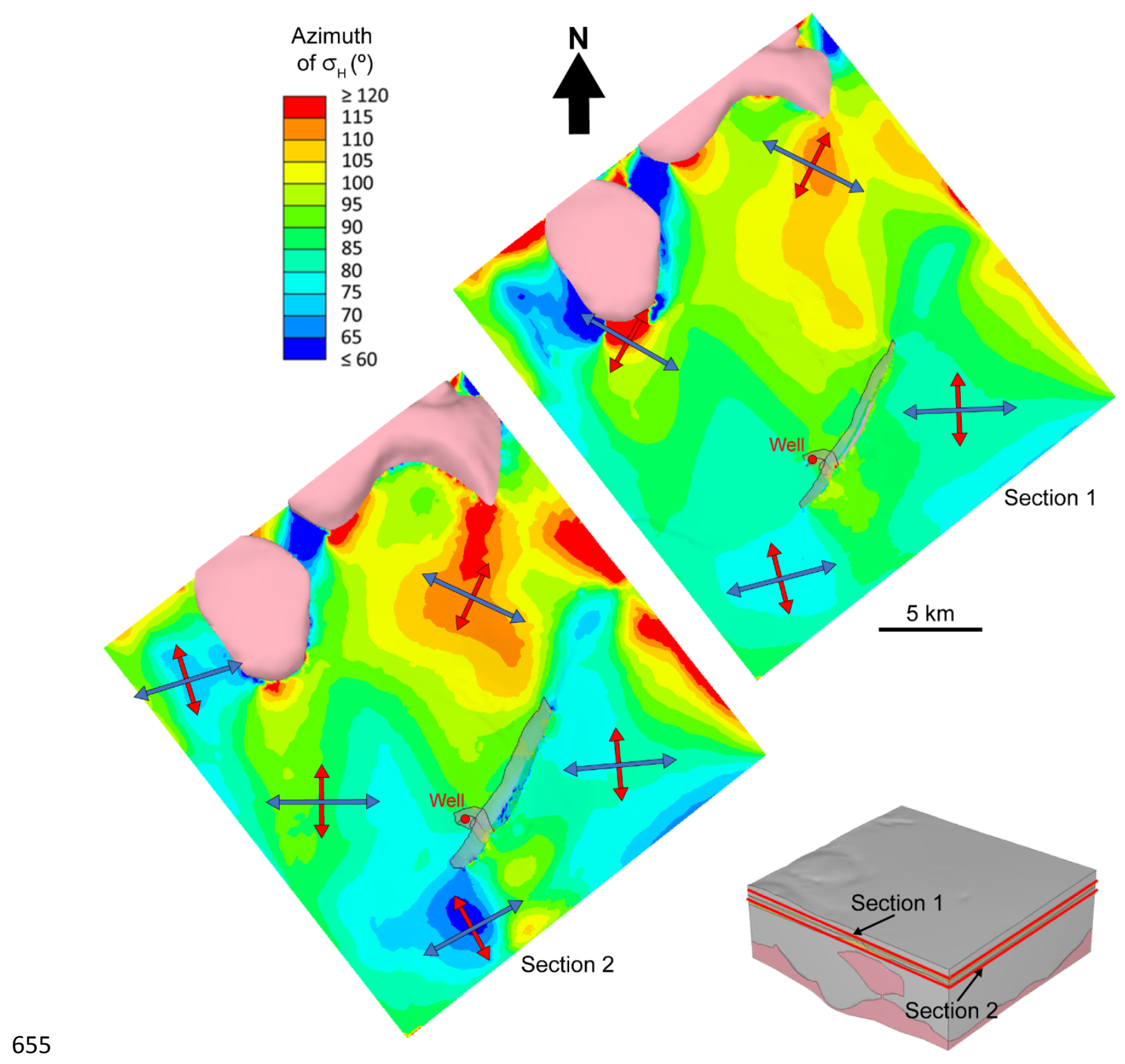

656 Fig. 6. Orientation of maximum and minimum horizontal stresses, $\sigma_{H}$ and $\sigma_{h}$, for two horizontal 657 sections of the 3D model. Contours represent the azimuth of the $\sigma_{H}$. The blue and red arrows 658 illustrate the directions of $\sigma_{H}$ and $\sigma_{h}$, respectively. The original east-west direction of $\sigma_{H}$ changes 659 in locations near the salt structures and around the major fault. 


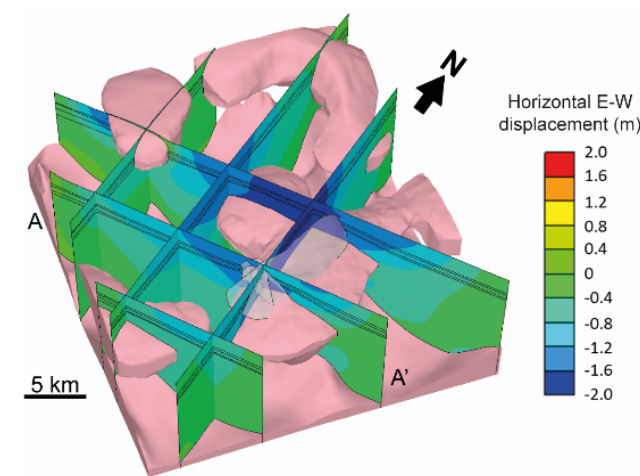

(a) Horizontal E-W displacement results across 3D model

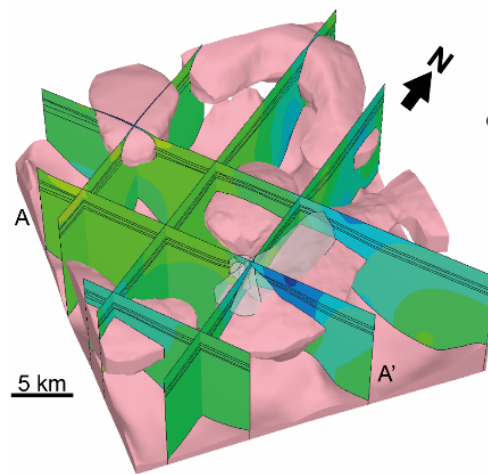

(c) Vertical displacement results across 3D model

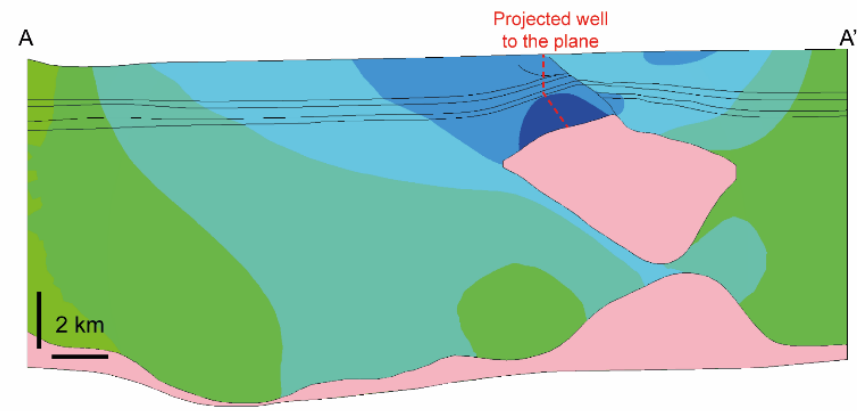

(b) Horizontal E-W displacement results at section A-A

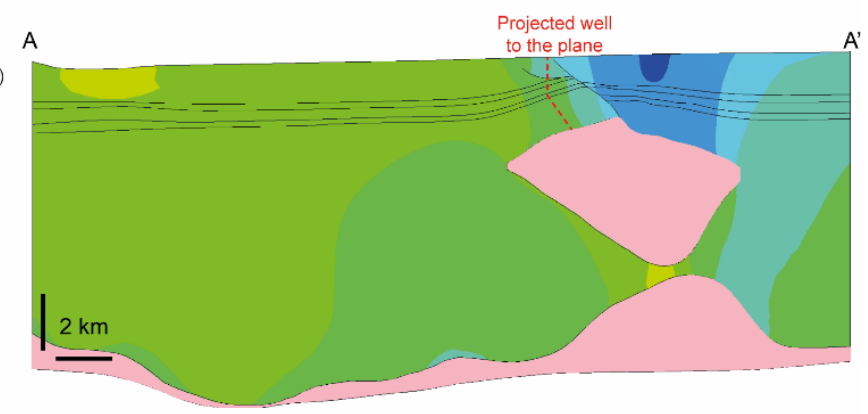

(d) Vertical displacement results at section A-A'

662 Fig. 7. (a) Horizontal east-west displacements across the model, showing mostly westward displacements (blue contours) concentrated above the eastern diapir and around the major fault. (b) Horizontal east-west displacements for section A-A' (shown in a) passing near the well location, displaying greater westward displacements for the sediments in the footwall compared to the hanging wall. (c) Vertical displacements across the model, showing downward movement (blue contours) in the hanging wall of the major fault. (d) Vertical displacements for section A$A^{\prime}$ (shown in c) passing near the well location. 


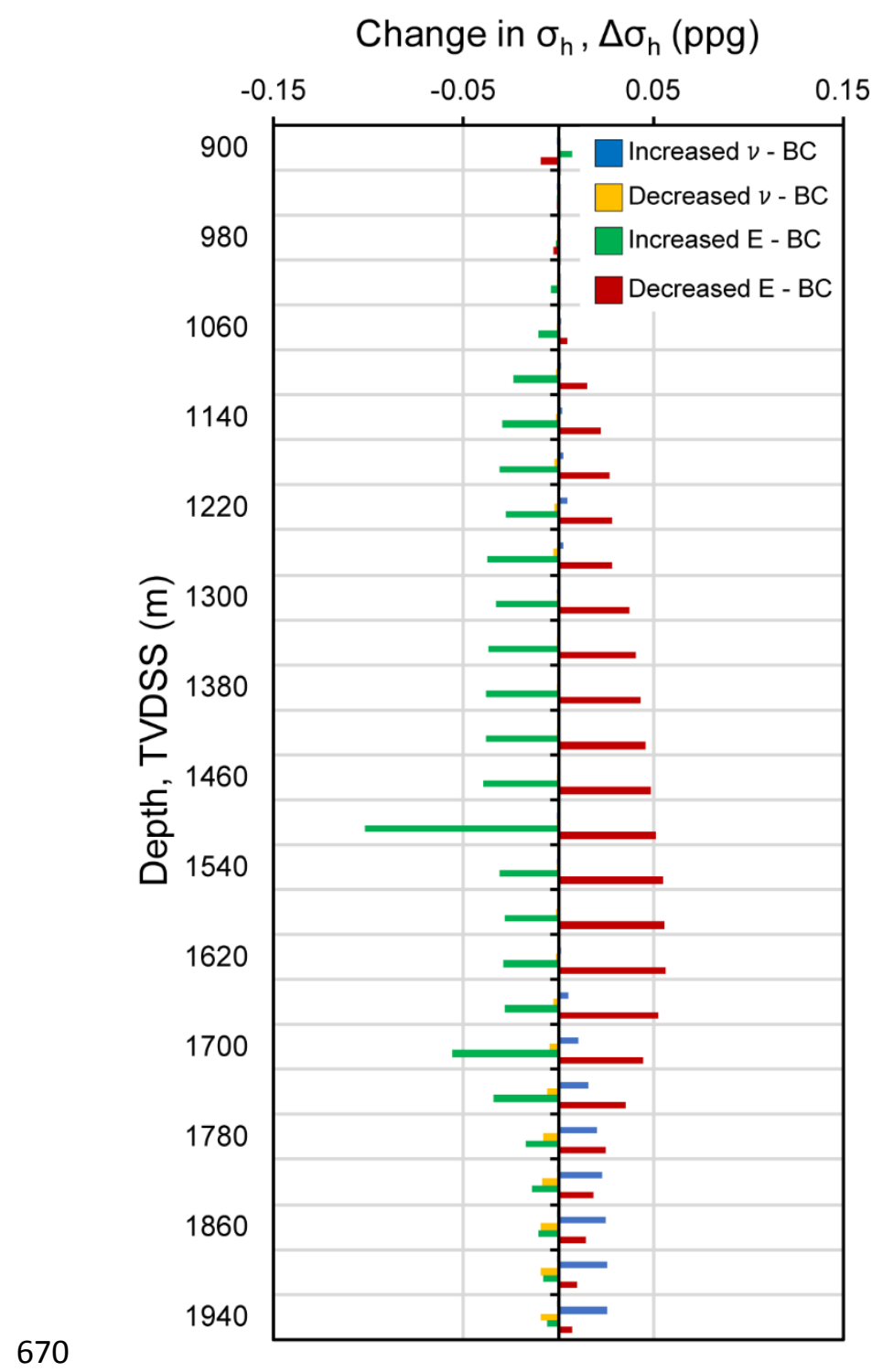

671 Fig. 8. Difference in prediction of horizontal stress $\sigma_{h}$ between sensitivity analysis and basecase 672 models along the first $1,000 \mathrm{~m}$ of the exploration well. The major difference is obtained when 673 varying the Elastic Modulus, but it does not exceed 0.15 ppg. This indicates little effect of the 674 elastic parameter variation on horizontal stress. 


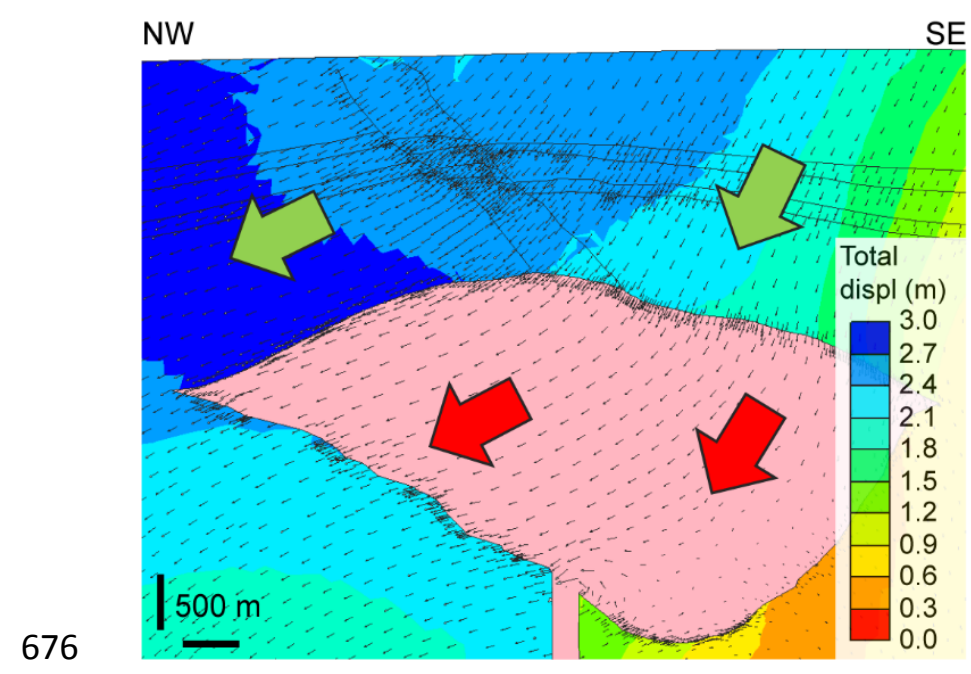

677 Fig. 9. Displacements of salt at the eastern diapir and the sediments encasing it. Salt 678 displacements (red arrows) show a downwards movement for the Eastern side of the diapir and 679 a westwards movement for its western side. Sediment displacements above the diapir (green 680 arrows) follow a pattern similar to the salt displacements. Colour contours indicate magnitudes 681 of displacements for the sediments. 


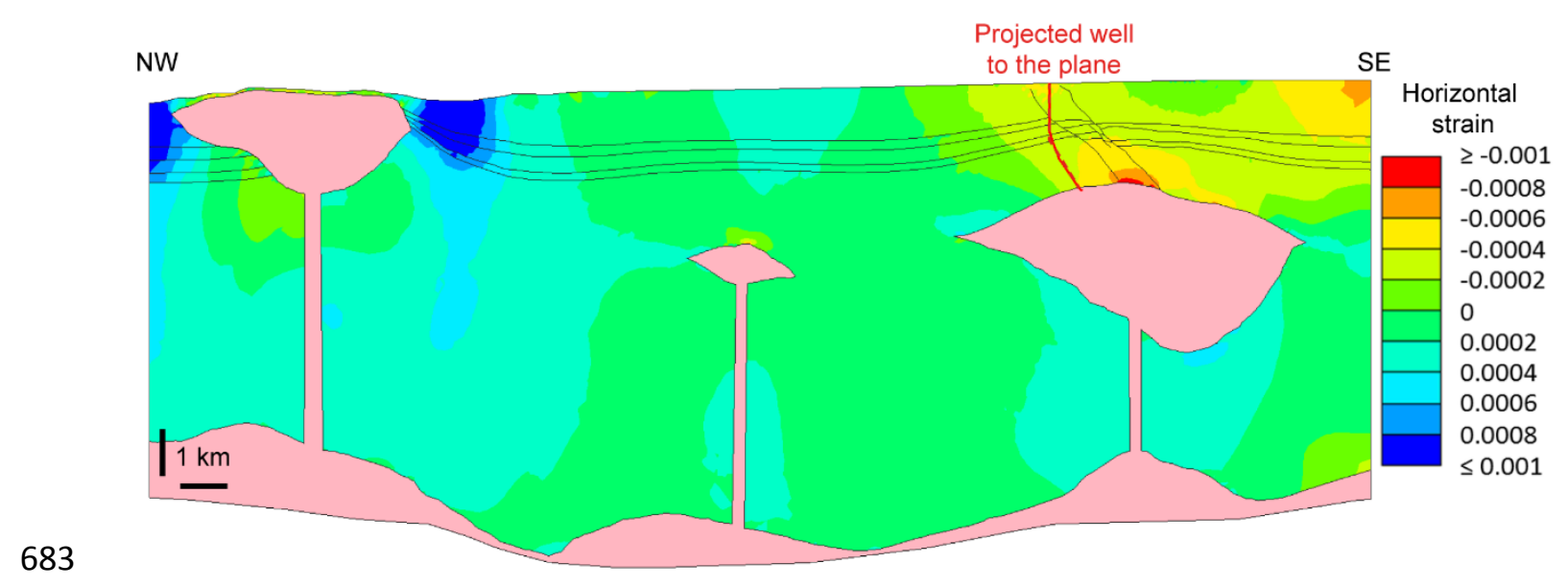

684 Fig. 10. Horizontal strain across the 2D model. Red contours represent extensional strains and 685 blue contours represent shortening strains. A region of extensional horizontal strain develops at 686 the crest of the eastern diapir, between the two faults. Shortening horizontal strains develop at 687 both sides of the western diapir. 


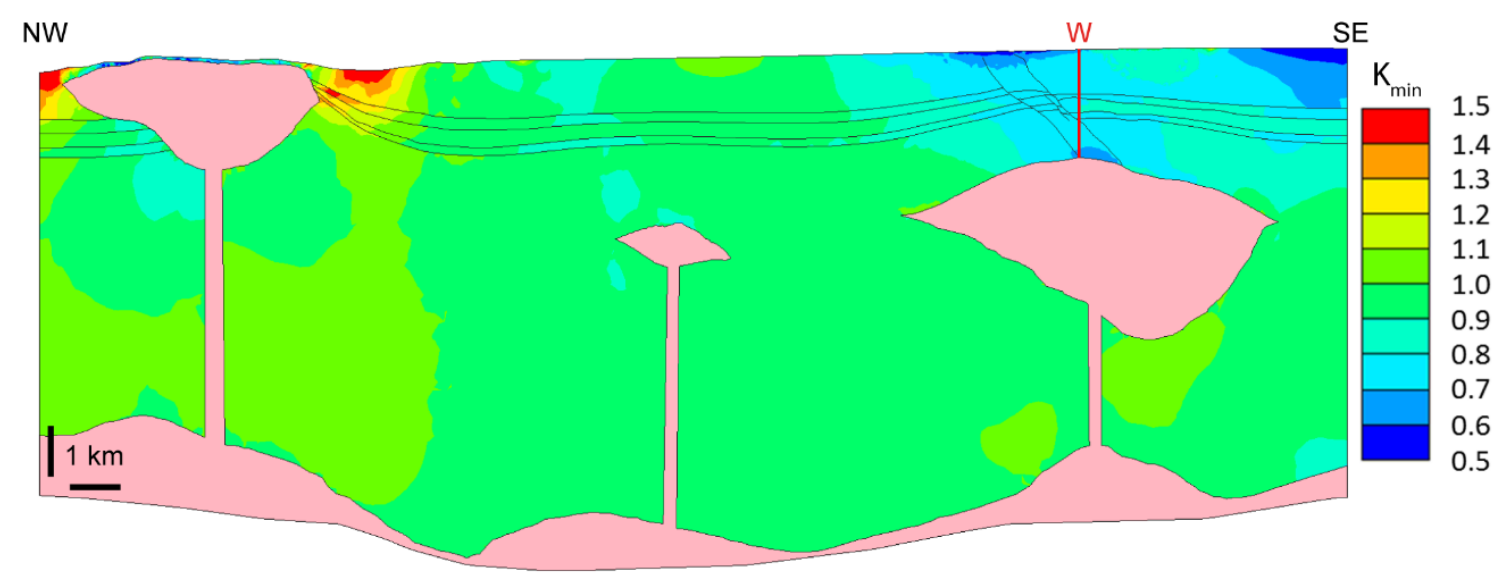

(a) $\mathrm{K}_{\min }$ results for the $2 \mathrm{D}$ model

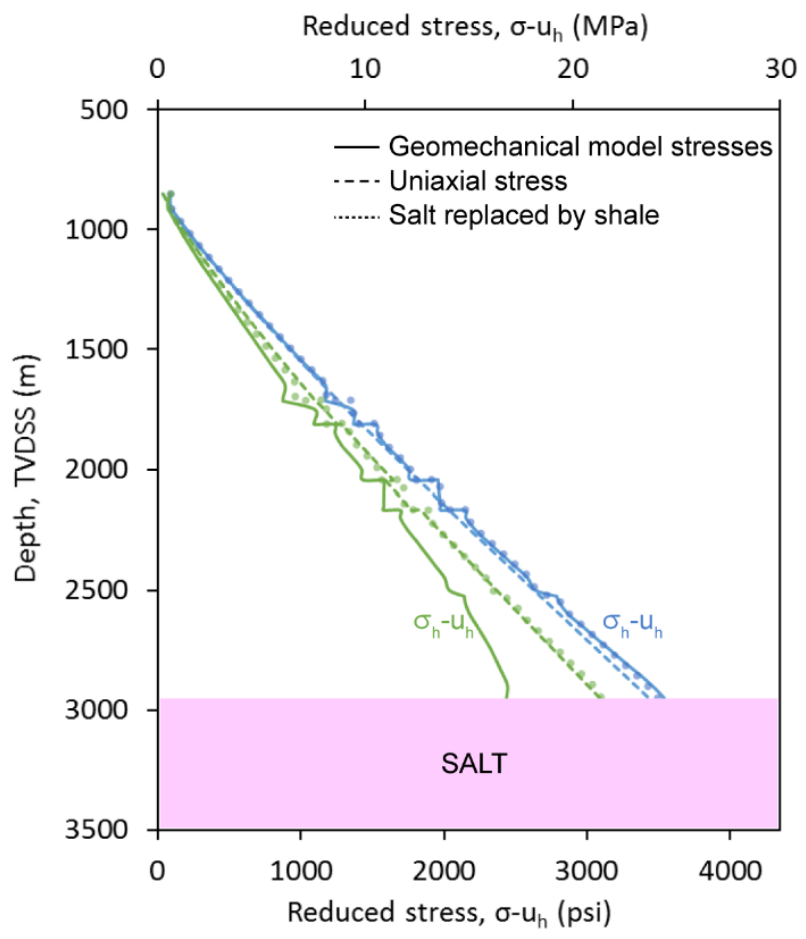

(b) Stress profile along well $\mathrm{W}$

690 Fig. 11. (a) Horizontal to vertical stress ratio predicted by the 2D model. The ratio changes near the salt structures, compared to its initial value of 0.8 (green contours). Specifically, it decreases above the eastern diapir, reaching values around 0.6. (b) Geomechanical prediction (solid lines) for horizontal (green) and vertical (blue) stress along a vertical profile W compared with uniaxial stresses (dashed lines) and model where salt is replaced by shale (dotted lines). Geomechanical horizontal stress is lower than uniaxial, reaching a maximum difference of $4.5 \mathrm{MPa}$ at the saltsediment interface. When salt is replaced by shale, there is no stress reduction and stresses are close to uniaxial conditions. 


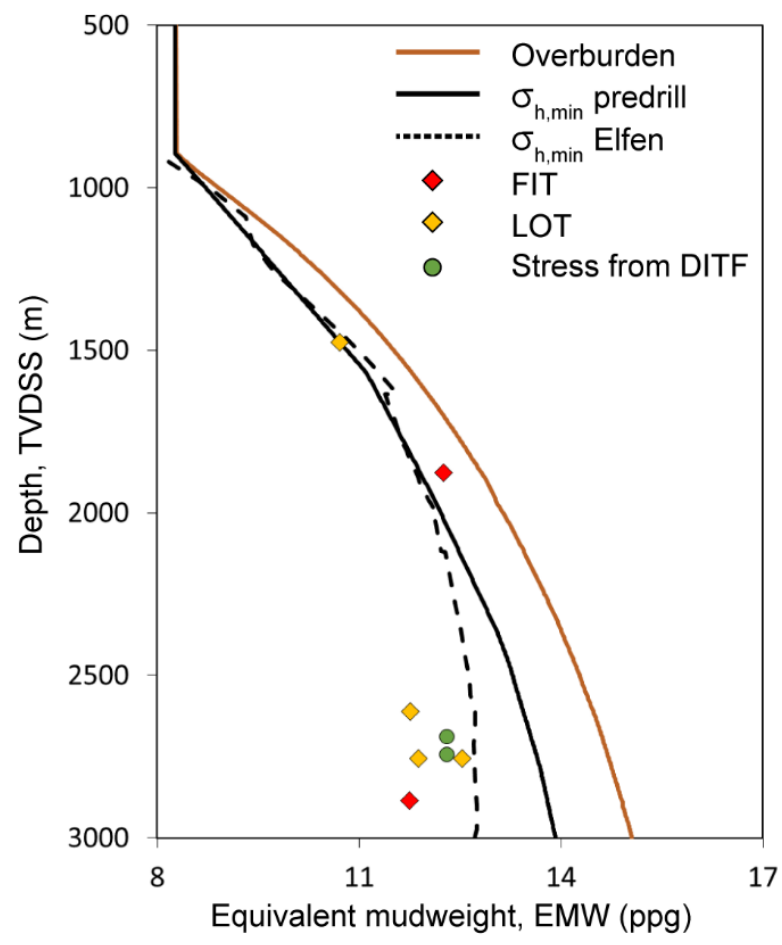

Fig. 12. Profile along exploration well (Fig. 3) comparing minimum horizontal stress, $\sigma_{\mathrm{h}}$ from the predrill study (solid black line) with $\sigma_{\mathrm{h}}$ predicted by the 3D model (dashed black line). The decrease of $\sigma_{\mathrm{h}}$ near the salt interface $(\mathrm{at} 3,000 \mathrm{~m}$ ) predicted by the 3D model was validated by data obtained during the drilling operations, including leak-off tests (LOT) measurements, formation integrity tests (FIT) measurements and the drilling induce tensile fractures (DITF) observed (yellow, red and green dots, respectively). Overburden stress, $\sigma_{\vee}$ shown with solid orange line. 


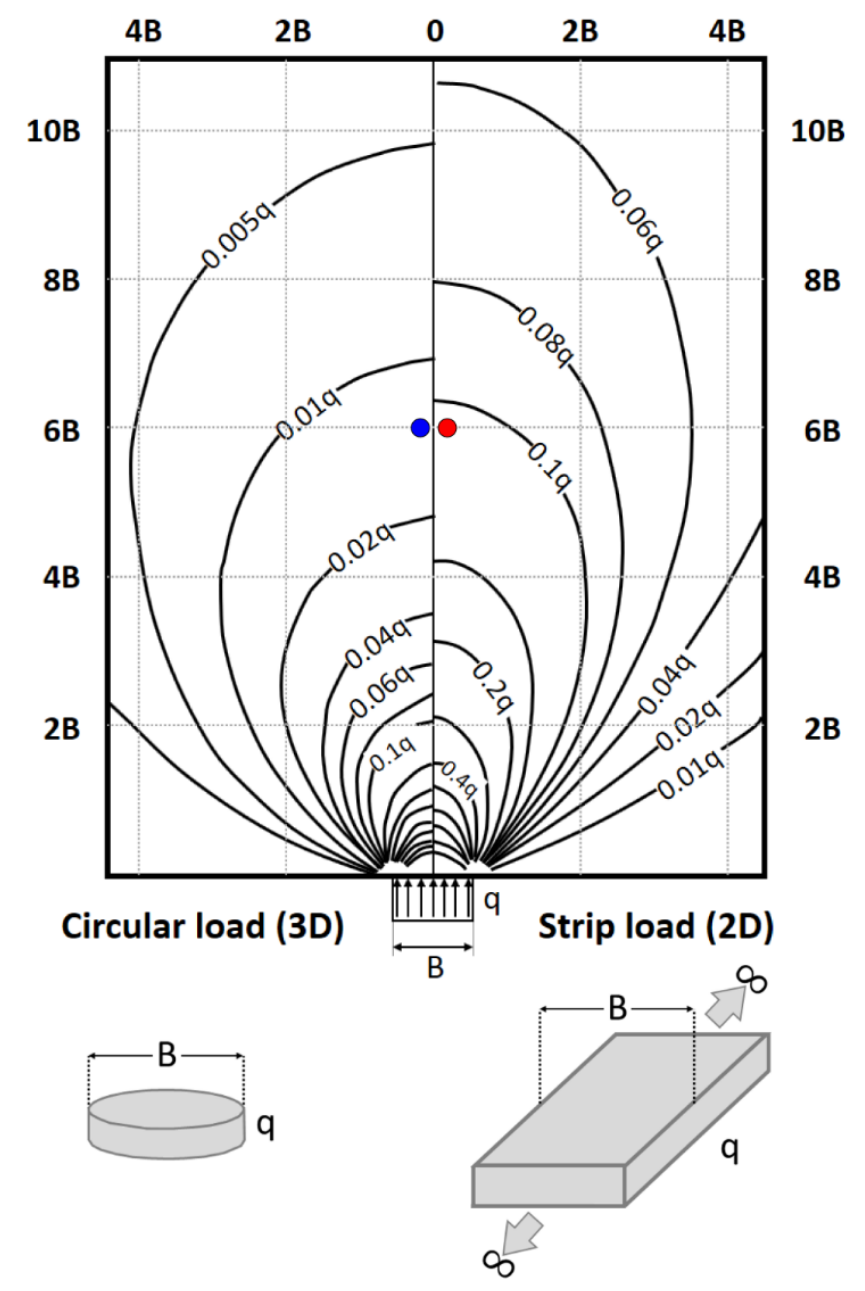

709 Fig. 13. Illustration of the solution for the vertical stress distribution in an elastic, semi-infinite 710 medium caused by the application of a 2D load (represented as a strip load) and a 3D load 711 (represented as a circular load) using the solution from Boussinesq (1885). There is no gravity 712 load. Blue and red dots correspond to the values of vertical stress at $6 \mathrm{~m}$ from the load for the $7133 \mathrm{D}$ and 2D case, respectively, where $\mathrm{B}=1 \mathrm{~m}$ and $q=1 \mathrm{MPa} / \mathrm{m}$. Modified from US Army Corps of 714 Engineers (1990). 


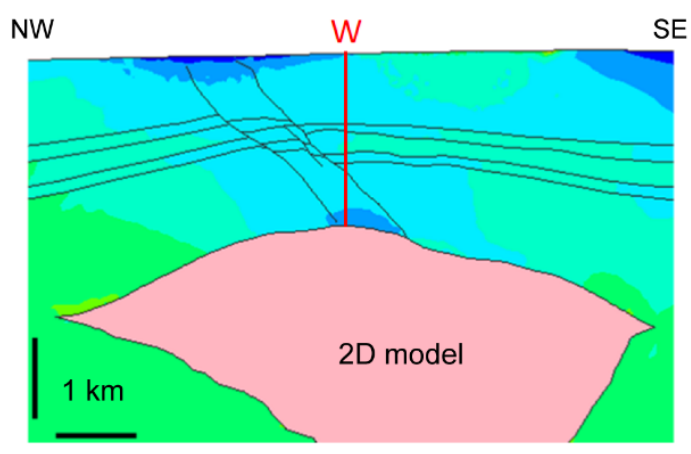

716

(a) $\mathrm{K}_{\min }$ results above Eastern diapir for $2 \mathrm{D}$ model

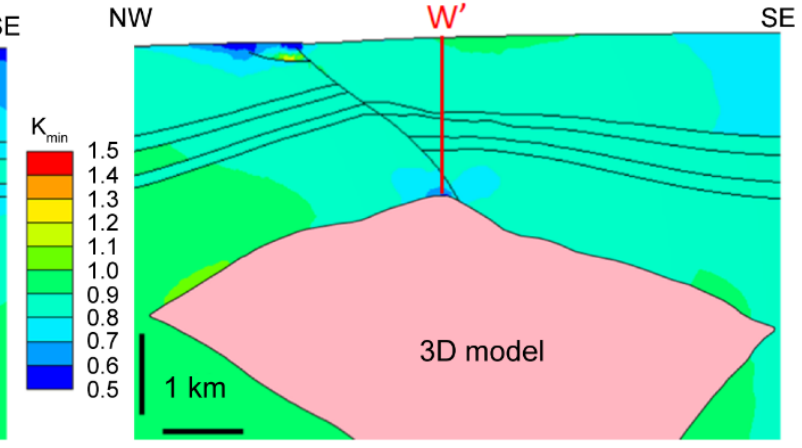

(b) $\mathrm{K}_{\min }$ results above Eastern diapir for 3D model

717 Fig. 14. Horizontal to vertical stress ratio predicted for sediments above the eastern diapir for (a) the 2D model and (b) the 3D model. Both models present a reduction of stress ratio of about 0.6 at the crest of the structure, compared with the initial 0.8. However, the reduction in the 2D model affects a broader area above the diapir. Vertical profiles $W$ and $W^{\prime}$ are used to quantitatively compare the stress change between the 2D and 3D model (Fig. 15). 


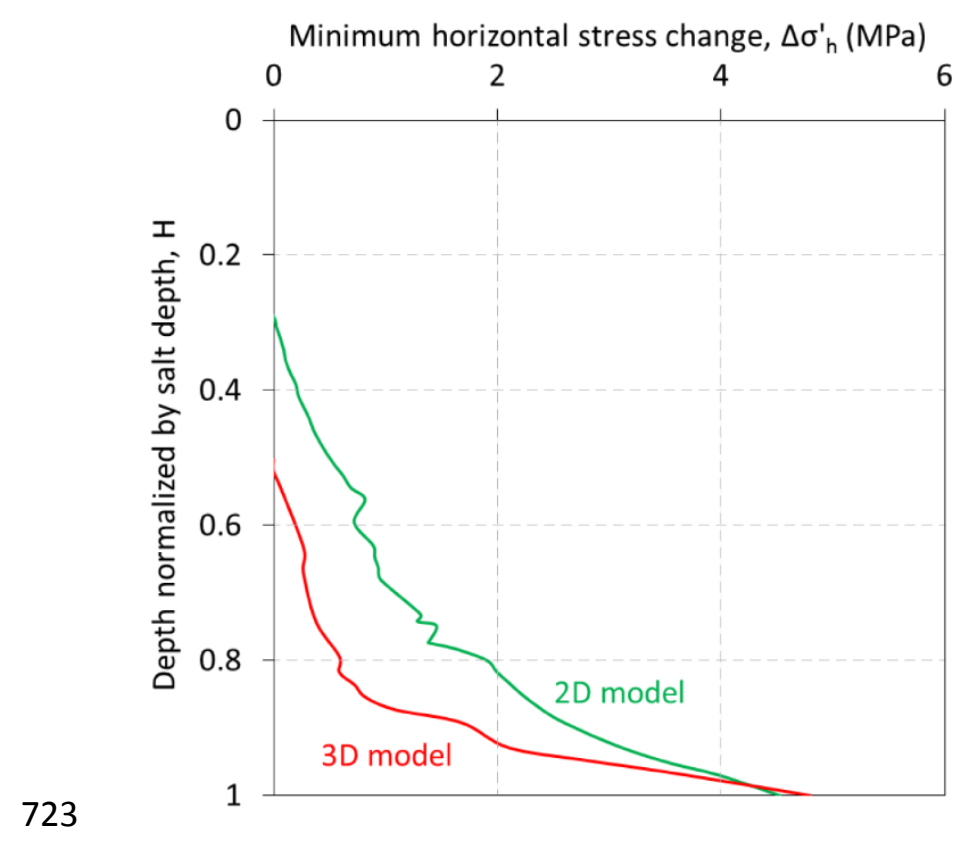

724 Fig. 15. Horizontal stress change with depth normalized by salt depth for both 2D (green line) 725 and 3D (red line) models along vertical profiles W and W' (Fig. 14) above the salt body. The stress 726 perturbation due to salt attenuates faster with distance from the salt body in the 3D model 727 compared to the $2 \mathrm{D}$ case. 
Table 1. Summary of input properties for the different horizon layers defined in the 3D model. Grain and fluid densities for the first four layers are $2650 \mathrm{Kg} / \mathrm{m}^{3}$ and $1025 \mathrm{Kg} / \mathrm{m}^{3}$, respectively and are $2600 \mathrm{Kg} / \mathrm{m}^{3}$ and $1300 \mathrm{Kg} / \mathrm{m}^{3}$, respectively, for the deepest shale layer (S3)

\begin{tabular}{|c|c|c|c|c|c|c|c|c|c|}
\hline Stratigraphy & Description & $\begin{array}{c}\text { Depth at } \\
\text { well } \\
\text { location }(\mathrm{m})\end{array}$ & $\begin{array}{c}\rho_{\mathrm{s}} \\
\left(\mathrm{Kg} / \mathrm{m}^{3}\right)\end{array}$ & $\begin{array}{c}\rho_{\mathrm{f}} \\
\left(\mathrm{Kg} / \mathrm{m}^{3}\right)\end{array}$ & $\begin{array}{c}\text { Overpressure } \\
\text { (MPa) }\end{array}$ & $\mathbf{v}$ & $\begin{array}{l}\text { Range } \\
\text { of } E \\
\text { (MPa) }\end{array}$ & $K_{h}$ & $K_{H}$ \\
\hline S1 & $\begin{array}{l}\text { Shales and } \\
\text { siltstones }\end{array}$ & $885-1600$ & 2650 & 1025 & - & 0.3 & $\begin{array}{l}290- \\
2250\end{array}$ & 0.73 & 0.87 \\
\hline R1 & Sand & $1600-1746$ & 2650 & 1025 & 0.9 & 0.3 & 2500 & 0.77 & 0.89 \\
\hline S2 & $\begin{array}{l}\text { Shales with } \\
\text { silt in upper } \\
\text { region }\end{array}$ & $1746-1950$ & 2650 & 1025 & - & 0.3 & 2800 & 0.80 & 0.90 \\
\hline R2 & Sand & $1950-2075$ & 2650 & 1025 & 2.7 & 0.3 & 3100 & 0.75 & 0.88 \\
\hline S3 & $\begin{array}{c}\text { Shales and } \\
\text { siltstones }\end{array}$ & 2075 - 3100 & 2600 & 1300 & 1.3 & 0.3 & $\begin{array}{l}3650- \\
50000\end{array}$ & 0.80 & 0.90 \\
\hline
\end{tabular}

Table 2. Summary of sensitivity analysis for the 3D static model

\begin{tabular}{ccc}
\hline Variable changed & Original value & Modified value \\
\hline Poisson's Ratio & 0.3 & 0.25 \\
& & 0.4 \\
\hline Elastic Modulus & $\begin{array}{c}\text { Horizon and depth } \\
\text { dependent (Table 1) }\end{array}$ & $\begin{array}{c}\text { increased 20\% } \\
\text { decreased 20\% }\end{array}$ \\
\hline
\end{tabular}


Table 3. Statistical summary of sensitivity analysis results, reporting comparison ratio $S$ (eq 6 )

\begin{tabular}{|c|c|c|c|c|c|c|c|}
\hline & & $\sigma_{1}$ & $\sigma_{2}$ & $\sigma_{3}$ & $\begin{array}{c}\text { E-W } \\
\text { displacement o }\end{array}$ & $\begin{array}{c}\mathrm{N}-\mathrm{S} \\
\text { displacement }\end{array}$ & $\begin{array}{c}\text { Vertical } \\
\text { displacement }\end{array}$ \\
\hline \multirow{4}{*}{ Increase v } & Average & $-4.45 E-05$ & 7.34E-05 & $-1.70 \mathrm{E}-05$ & $1.02 \mathrm{E}-03$ & 7.06E-04 & $-3.87 \mathrm{E}-03$ \\
\hline & Median & $-2.40 \mathrm{E}-05$ & $-2.70 \mathrm{E}-05$ & $-2.00 \mathrm{E}-06$ & $2.08 \mathrm{E}-03$ & $4.18 \mathrm{E}-04$ & $8.60 \mathrm{E}-05$ \\
\hline & Stand. Dev & 5.07E-03 & $3.02 \mathrm{E}-03$ & $1.86 \mathrm{E}-03$ & 0.02 & 0.04 & 0.06 \\
\hline & Points omitted (\%) & $1.80 \mathrm{E}-03$ & $2.28 \mathrm{E}-04$ & 0 & 0.04 & 0.13 & 0.47 \\
\hline \multirow{4}{*}{ Decrease $v$} & Average & $3.02 \mathrm{E}-05$ & $-5.09 \mathrm{E}-05$ & $-9.71 \mathrm{E}-07$ & $-2.75 \mathrm{E}-04$ & $-1.97 \mathrm{E}-03$ & $3.42 \mathrm{E}-03$ \\
\hline & Median & $6.00 \mathrm{E}-06$ & $4.00 \mathrm{E}-06$ & $-1.00 \mathrm{E}-06$ & $-9.10 \mathrm{E}-04$ & $-1.10 \mathrm{E}-05$ & $-1.07 E-04$ \\
\hline & Stand. Dev & $2.43 \mathrm{E}-03$ & $1.26 \mathrm{E}-03$ & $6.44 \mathrm{E}-04$ & 0.01 & 0.03 & 0.04 \\
\hline & Points omitted (\%) & 4.06E-04 & $5.07 \mathrm{E}-05$ & 0 & 0.02 & 0.08 & 0.20 \\
\hline \multirow{4}{*}{ Increase E } & Average & $-3.62 \mathrm{E}-05$ & $-3.34 \mathrm{E}-04$ & $-7.21 \mathrm{E}-05$ & 0.15 & 0.12 & 0.18 \\
\hline & Median & $9.10 \mathrm{E}-05$ & $-3.71 E-04$ & 3.90E-05 & 0.16 & 0.16 & 0.15 \\
\hline & Stand. Dev & 0.02 & $6.84 \mathrm{E}-03$ & $3.14 \mathrm{E}-03$ & 0.04 & 0.09 & 0.11 \\
\hline & Points omitted (\%) & 0.02 & $2.46 \mathrm{E}-03$ & 0 & 0.15 & 0.83 & 1.31 \\
\hline \multirow{4}{*}{ Decrease E } & Average & $-4.19 E-05$ & $4.02 \mathrm{E}-04$ & $6.03 \mathrm{E}-05$ & -0.21 & -0.15 & -0.30 \\
\hline & Median & $-2.24 \mathrm{E}-04$ & 5.37E-04 & $-4.70 \mathrm{E}-05$ & -0.22 & -0.22 & -0.21 \\
\hline & Stand. Dev & 0.02 & $7.90 \mathrm{E}-03$ & $3.87 \mathrm{E}-03$ & 0.06 & 0.12 & 0.14 \\
\hline & Points omitted (\%) & 0.03 & $3.35 \mathrm{E}-03$ & 0 & 0.25 & 1.43 & 2.42 \\
\hline
\end{tabular}

Table 4. Summary of sensitivity analysis run for the 2D static model

\begin{tabular}{ccc}
\hline Variable changed & Original value & Modified value \\
\hline Poisson's Ratio & 0.3 & 0.25 \\
& & 0.4 \\
\hline Young Modulus & $\begin{array}{c}\text { Horizon and depth } \\
\text { dependent (Table 1) }\end{array}$ & $\begin{array}{c}\text { increased } 20 \% \\
\text { decreased } 20 \%\end{array}$ \\
\hline Salt replaced by shale & Salt & Shale \\
\hline Flattened seafloor & $1^{\circ}$ seafloor slope & Horizontal seafloor \\
\hline Number of diapir & 3 diapirs & 1 diapir (eastern diapir) \\
\hline Width of salt columns & $200 \mathrm{~m}$ & $400 \mathrm{~m}$ \\
\hline
\end{tabular}




\section{APPENDIX A: NOMENCLATURE}

Table A1. Nomenclature

\begin{tabular}{lll}
\hline Symbol & Name & Dimensions \\
\hline$E$ & Elastic (Young's) Modulus & $L^{-1} M^{1} T^{-2}$ \\
$K_{H}$ & Maximum initial stress ratio & $L^{0} M^{0} T^{0}$ \\
$K_{h}$ & Minimum initial stress ratio & $L^{0} M^{0} T^{0}$ \\
$n$ & Porosity & $L^{0} M^{0} T^{0}$ \\
$p^{\prime}$ & Mean effective stress & $L^{-1} M^{1} T^{-2}$ \\
$S$ & Comparison ratio (eq. 6) & $L^{0} M^{0} T^{0}$ \\
$\lambda$ & Normalized horizontal stress change ratio & $L^{0} M^{0} T^{0}$ \\
$v$ & Poisson's Ratio & $L^{0} M^{0} T^{0}$ \\
$\rho_{b}$ & Bulk density & $L^{-3} M^{1} T^{0}$ \\
$\rho_{s}$ & Density of sediments & $L^{-3} M^{1} T^{0}$ \\
$\rho_{w}$ & Density of fluid & $L^{-3} M^{1} T^{0}$ \\
$\sigma^{\prime}$ & Effective stress & $L^{-1} M^{1} T^{-2}$ \\
$\sigma_{v}$ & Vertical stress & $L^{-1} M^{1} T^{-2}$ \\
$\sigma_{H}$ & Maximum horizontal stress & $L^{-1} M^{1} T^{-2}$ \\
$\sigma_{h}$ & Minimum horizontal stress & $L^{-1} M^{1} T^{-2}$ \\
$\sigma_{1}$ & Maximum principal stress & $L^{-1} M^{1} T^{-2}$ \\
$\sigma_{2}$ & Intermediate principal stress & $L^{-1} M^{1} T^{-2}$ \\
$\sigma_{3}$ & Minimum principal stress & $L^{-1} M^{1} T^{-2}$ \\
\hline & & \\
\hline & &
\end{tabular}


1

2

3

4

5

6

7

8

9

10

11

12

APPENDIX B: MATERIAL INPUT

Table B1. Input material parameter values for poro-elastic sediments (sands and shales)

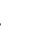

5

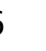

\begin{tabular}{lccccc}
\hline & $\mathbf{E}_{\text {ref }}$ (MPa) & A (MPa) & B (MPa) & r & c \\
\hline Shallow shales (S1) & 100 & -1 & -1 & 0.4 & -2.1 \\
Sands (R1) & 2500 & -1 & -1 & 0 & 0 \\
Intermediate shales (S2) & 2800 & -1 & -1 & 0 & 0 \\
Sands (R2) & 3100 & -1 & -1 & 0 & 0 \\
Deep shales (S3) & 150 & -1 & -1 & 0.55 & -1.4 \\
\hline
\end{tabular}

Table B2: Input material parameter values for viscoplastic Munson-Dawson model (Munson 1997; Fredrich et al. 2007b)

\begin{tabular}{ccc}
\hline Parameter & Units & Value \\
\hline $\mathrm{E}$ & $\mathrm{Mpa}$ & 31000 \\
$v$ & & 0.25 \\
$\rho$ & $\mathrm{Kg} / \mathrm{m}^{3}$ & 2100 \\
$\mathrm{~A}_{1}$ & $1 / \mathrm{s}$ & $5.95 \mathrm{E}+22$ \\
$\mathrm{~N}_{1}$ & & 5.5 \\
$\mathrm{Q}_{1}$ & $\mathrm{cal} / \mathrm{mol}$ & 25000 \\
$\mathrm{~A}_{2}$ & $1 / \mathrm{s}$ & $6.87 \mathrm{E}+12$ \\
$\mathrm{~N}_{2}$ & & 5 \\
$\mathrm{Q}_{2}$ & $\mathrm{cal} / \mathrm{mol}$ & 10000 \\
$\mathrm{R}$ & $\mathrm{cal} /{ }^{\circ} \mathrm{K} / \mathrm{mol}$ & 1.987 \\
$\mathrm{~T}_{0}$ & ${ }^{\circ} \mathrm{K}$ & 0 \\
$\mathrm{~T}_{\text {const }}$ & ${ }^{\circ} \mathrm{K}$ & 273 \\
$\mathrm{G}_{0}$ & $\mathrm{MPa}$ & 12400 \\
$\mathrm{dG} / \mathrm{dT}$ & $\mathrm{MPa} /{ }^{\circ} \mathrm{K}$ & 10 \\
\hline & &
\end{tabular}

